\title{
La obra del arquitecto Lorenzo González Iglesias (1906-1964)
}

\author{
The work of the architect Lorenzo González \\ Iglesias (1906-1964)
}

\author{
Sara NÚÑEZ IZQUIERDO \\ Universidad de Salamanca
}

Recibido: 23-IV-2014 / Aceptado: 21-VI-2014

Resumen: En 1933 Lorenzo González finalizó sus estudios en la Escuela Superior de Arquitectura de Madrid y, dos años después, se estableció en Salamanca, donde desarrolló el grueso de su producción. Fallecido en 1964, a lo largo de los veintinueve años de carrera profesional abordó variados asuntos artísticos, arquitectónicos y otros propios de su condición de arquitecto municipal. A su vez, dejó constancia de sus ideas y preocupaciones sobre estos temas a través de artículos publicados en la prensa, además de investigar sobre la arquitectura y las tradiciones de algunos parajes de la provincia salmantina. Por lo demás, fue un destacado representante del racionalismo, el historicismo y las propuestas renovadoras de los años cincuenta.

Palabras clave: Lorenzo González, Racionalismo, Historicismo, Arquitectura popular.

ABSTRACT: In 1933 Lorenzo Gonzalez Iglesias finished his studies in Madrid and two years later he spent the rest of his life in Salamanca. He died in 1964 and during those years he worked as principal architect of the city, and so resolved many architectural questions. Iglesias was concerned with the structural regulation and focused on the conservation of the architectural corpus of Salamanca, reason why he discussed the new buildings and wrote about them in newspapers. Even though he was employed as council architect, he designed important buildings in Salamanca.

Keywords: Lorenzo González, Rationalism, Historicism, Popular architecture.

El arquitecto Lorenzo González Iglesias nació en Ávila en 1906 y fue hijo de Lorenzo González Ramírez (nacido en 1866), ayudante de obras públicas, natural de Miraflores de la Sierra (Madrid), y de Luisa Iglesias Jesús (nacida en 1876), oriunda de Puen- te del Congosto (Salamanca) (Fig. 1) ${ }^{1}$. Escasas son las noticias halladas del periplo vital

${ }^{1}$ En la partida de nacimiento quedó reflejado su nombre completo: Lorenzo Nazario Cipriano González Iglesias. Archivo General de la Administración Alcalá de Henares, (en adelante AGAAH), Fondo Educación, Documento (05) 020 32/15126, Legajo 8574/57. 
de este matrimonio, fruto del cual nacieron dos hijos: Víctor y el técnico que nos ocupa.

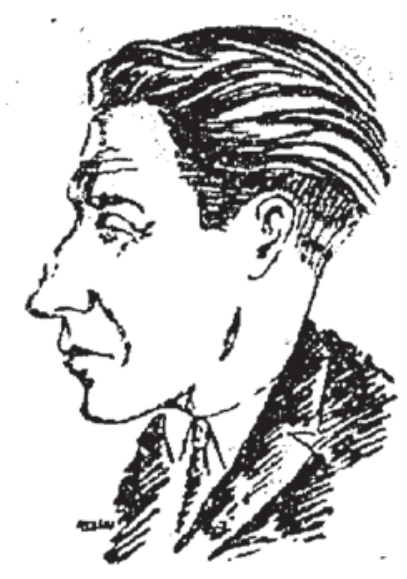

- Fig. 1. Dibujo de Lorenzo González Iglesias. Publicado en La Gaceta Regional, julio 1963.

Inicialmente, Lorenzo González comenzó la carrera de aparejador en 1922 en la Escuela Industrial de Madrid que terminó dos años después². Todo indica que sus aspiraciones eran más ambiciosas, ya que hasta 1933 no solicitó el correspondiente título y no tenemos constancia de que ejerciese como tal. Así las cosas, decidió continuar con su formación en la Escuela Superior de Arquitectura de Madrid, en la que ingresó en 1926, tras haber cursado las asignaturas preparatorias de acceso en la Universidad de Salamanca, titulándose como arquitecto en 1933. Por aquel entonces, Modesto López Otero (1885-1962; titulado en 1910) era el director y también profesor de la Escuela. Por otro lado, tenemos noticia de que González Iglesias fue compañero de facultativos que desarrollaron una dilatada carrera proyectual en algunas de las principales capitales de provincias castellanas. Estos, al igual que el técnico objeto de este artículo, se iniciaron con el racionalismo y, tras el obligado viraje impuesto por el Nuevo Estado, apostaron por varias tentativas dentro del historicismo.

2 Ibídem, Fondo Educación, Documento (05) 020 32/15120, Legajo 8571/50. Dato publicado por primera vez en S. NÚÑEZ IZQUIERDO, La tipología de la vivienda en la arquitectura salmantina del Primer Franquismo (1939-1953). Trabajo Fin de Máster, Salamanca, 2011, pp. 852-858.
Así, cabe citar, por ejemplo, al burgalés Marcos Rico Santamaría (1908-1995; titulado en 1933), al palentino Ambrosio Arroyo Alonso (nacido en 1905; titulado en 1933) y al zamorano Antonio Viloria Gómez-Villaboa (19011991; titulado en 1933).

Centrados en Lorenzo González, hay que señalar que los años que transcurrió en Madrid tuvo la oportunidad de conocer algunos de los mejores ejemplos de varias corrientes de la arquitectura española del primer tercio del siglo XX. Estos inmuebles se clasifican dentro del expresionismo, del art déco, del racionalismo, etc., caso, por ejemplo, de la Casa de las Flores (1931) de Secundino Zuazo Ugalde (1887-1971; titulado en 1912), el cine San Carlos (1928) de Eduardo Lozano Lardet (1897-1968; titulado en 1923), la gasolinera de Porto Pí (1927) de Casto Fernández Shaw Iturralde (1896-1978; titulado en 1919) o la desaparecida piscina La Isla (1931) de Luis Gutiérrez Soto (19001977; titulado en 1923), entre otros.

Desafortunadamente carecemos de noticias sobre González Iglesias desde 1933 hasta 1935, año en el que fijó su residencia y su estudio en la capital del Tormes, donde, por otra parte, desarrolló el grueso de su producción. Efectivamente, nos consta que, pese a haberse formado en la capital de España, allí no llevó a cabo ninguna obra y ni tampoco en Ávila, localidad de la que era natural. Su estudio en la capital charra estuvo instalado en un principio en un inmueble de la céntrica plaza de San Juan de Sahagún ${ }^{3}$, hasta su posterior traslado a otro en la calle Azafranal, aunque ninguno de estos dos edificios se conserva en la actualidad ${ }^{4}$.

Salamanca fue la ciudad donde transcurrió la mayor parte de la vida de este arquitecto -a excepción de los meses que luchó en el frente en 1938-, años que compartió con su mujer Celia Iglesias Amén y sus tres hijos.

${ }^{3}$ Lista General de los arquitectos españoles: 1936, Madrid, 1936, p. 85.

${ }^{4}$ Lista General de los arquitectos españoles: 1944, Madrid, 1944, p. 74. 
Fue aquí también donde falleció el dieciséis de octubre de 1964, a la edad de cincuenta y siete años, aquejado de cáncer, por lo que su muerte fue dolorosamente esperada. Así se desprende de la necrológica que apareció en la prensa: "minó pronto su agilidad", demostró una gran entereza hasta sus últimos días. Fue recordado como un "hombre bueno, sencillo, honrado, excelente conversador y amigo de todos" (...) y como "uno de los más positivos valores de la arquitectura con ideas nuevas y una gran vocación por su carrera" ${ }^{\prime}$. Muchas de sus virtudes fueron reconocidas al definirlo como "una persona de méritos bien probados, y de una capacidad creadora francamente sorprendente ${ }^{\prime 7}$ o como un arquitecto eficiente" ${ }^{\prime 8}$. "Don Lorenzo González Iglesias no sólo fue el arquitecto que retirado en su estudio elaboraba proyectos y resolvía a su leal saber y entender el difícil problema de crear sin merma de la belleza histórica y tradicional que era preciso conservar" (...) "sino que se identificó con Salamanca y fue un estudioso, realmente un investigador del arte y las bellezas salmantinas; como rescató igualmente temas y variantes de artesanas tradiciones amenazadas de desaparición" ${ }^{\prime 9}$.

El arquitecto que nos ocupa fue un gran aficionado a la música, sobre todo de zarzuela, género a cuyas representaciones asistió con frecuencia, por lo que tuvo amistad con autores tan conocidos como Federico Romero y Guillermo Fernández ${ }^{10}$.

\footnotetext{
5 “Ha muerto D. Lorenzo González Iglesias", La Gaceta Regional, 17-X-1964, p. 3.

6 "Notas de sociedad: Fallecimiento", El Adelanto, 17-X-1964, p. 2.

7 SANT-YAGO, "Al habla con... González Iglesias", El Adelanto, 2-VI-1954, p. 4.

8 "Piedra a piedra la ciudad cambia", La Gaceta Regional, 1-I-1955, p. 10.

9 "Ha muerto D. Lorenzo González Iglesias", La Gaceta Regional, 17-X-1964, p. 3.

10 "Notas de Sociedad: varias", El Adelanto, 15-XI1944, p. 4; "Peñamariana se estrenó ayer, en Madrid, con gran éxito", El Adelanto, 17-XI-1944, p. 4; A. GARCÍA BOIZA, "Ecos del estreno de Peñamariana", El Adelanto, 22-XI-1944, p. 4.
}

Tenemos constancia de que mantuvo excelentes relaciones con los principales artistas locales con quienes incluso expuso algunas de sus obras en muestras colectivas. En este sentido, en 1941 presentó los planos de uno de sus proyectos junto a los lienzos de Andrés Abraído del Rey, los dibujos de Julián Iglesias y las fotografías de Ramón Buxaderas ${ }^{11}$.

Como ya vimos, González Iglesias también tuvo contacto a nivel profesional con algunos escultores del panorama artístico local y nacional, por ejemplo con José Luis Núñez Solé, quien decoró algunos de los inmuebles estudiados en este artículo.

Además, por sus méritos a lo largo su vida Iglesias fue distinguido como académico correspondiente de la Real Academia de Bellas Artes de San Fernando en 1943 y miembro de la primera Junta rectora del Centro de Estudios Salmantinos en 1951, donde fue el máximo responsable de la sección de cultura popular ${ }^{12}$.

\section{SALAMANCA, ESCENARIO DE LAS OBRAS DE LORENZO GONZÁLEZ}

La trayectoria proyectual de este facultativo se dilató desde 1935 hasta 1964. Durante estos veintinueve años la ciudad de Salamanca experimentó notables cambios. En primer lugar, cabe señalar que, como capital de provincia, tuvo una relativa prosperidad como consecuencia del resurgimiento de su Universidad, sobre todo a partir de 1939.

Por otro lado, se da la circunstancia de que la Guerra Civil y sus nefastas consecuencias apenas afectaron a esta localidad, ya que se adhirió tempranamente al alza-

11 "Inauguración de la Exposición de Artistas Salmantinos", El Adelanto, 15-IV-1941, p. 8.

12 El abulense fue designado académico junto al pintor José Cruz Herrera, el escultor Federico Marés Deulovol, el músico Bonifacio Gil García y el conde de Bustillo por su labor vinculada con las Bellas Artes. "Vida académica: Real Academia de Bellas Artes de San Fernando", ABC, 18-III-1943, p. 13. 
miento y sólo sufrió un bombardeo en 1938. Este último se saldó con siete víctimas mortales y numerosos heridos, aparte de afectar a algunos de inmuebles situados en la zona centro $^{13}$.

El incremento demográfico experimentado en las décadas de los años treinta y, sobre todo, en la de los cuarenta transformó el paisaje como consecuencia de una intensa actividad constructiva en el centro de la ciudad, la conformación de una extensa periferia y la aparición de nuevos barrios.

A lo largo de esos años se redactaron cuatro planes de urbanismo con los que teóricamente se trató de regularizar el crecimiento urbano, aunque la realidad fue muy distinta, ya que la inviabilidad de algunas propuestas y la escasez de medios provocaron el efecto contrario. Cabe citar el fechado en 1937, data en la que el Ayuntamiento solicitó la elaboración del Proyecto de Reforma Interior y Ensanche. En un principio el encargo recayó en el colectivo de técnicos vinculados a la delegación del Colegio Oficial de Arquitectos de Salamanca, entre los que se encontraba Lorenzo González Iglesias. Sin embargo, esta corporación declinó la responsabilidad por considerar que, de esta manera, servía "mejor los intereses de la ciudad"14, aunque desconocemos los verdaderos motivos que se escondían tras estas buenas palabras. Así las cosas, el Consistorio decidió asignar la redacción del anteproyecto directamente al Servicio de Arquitectura de Falange, entonces dirigido por Pedro $\mathrm{Mu}$ guruza Otaño (1893-1952; titulado en 1916), y éste, a su vez, optó por asignarlo a su cole-

${ }_{13}$ Archivo Municipal de Salamanca (en adelante AMS), Fondo de obras, Caja 1768, Expediente 39; “El criminal bombardeo de ayer", La Gaceta Regional, 22-I1938, p. 1; "Varios aparatos rojos descargaron ayer su metralla mortífera sobre Salamanca", El Adelanto, 22-I1938, p. 1; M. BEGOÑA, "Después del bombardeo", La Gaceta Regional, 1-II-1938, p. 2; “Salamanca entera rindió ayer póstumo homenaje a las víctimas del cobarde bombardeo del viernes por la aviación roja", El Adelanto, 23I-1938, p. 2.

${ }^{14}$ AMS, Libro no 326. Actas de la Comisión Municipal Permanente. Sesión del 3 de mayo de 1938. fol. 161 v. ga Víctor d'Ors Pérez-Peix (1918-1994; titulado en 1940) ${ }^{15}$.

Efectivamente, el aumento incontrolado de la ciudad fue una de las preocupaciones de González Iglesias desde el año 1937, llegando a referirse al mismo como "el extrarradio desordenado y elefantiásico"16. Así, publicó seis artículos en el periódico El Adelanto, firmados con el pseudónimo del escultor renacentista, Vasco de la Zarza, donde se hizo eco y denunció las escasas medidas tomadas y el origen histórico de este descontrol, aparte de proponer lo que él consideraba el sistema idóneo de circulación de la ciudad ${ }^{17}$. De hecho, demostró su interés y preocupación por el devenir arquitectónico y urbanístico de Salamanca en los cargos que desempeñó dentro de la administración como facultativo de la Diputación, delegado provincial del Instituto Nacional de la Vi-

${ }^{15}$ Sobre el proyecto véase V. D'ORS PÉREZ-PÉIX, "Sobre el plan de urbanización de Salamanca", Revista Nacional de Arquitectura, no 1, 1941, pp. 51-65; F. MIRANDA REGOJO, Desarrollo urbanístico de posguerra en Salamanca, Salamanca, 1985, pp. 47-65; D. SENABRE LÓPEZ, Desarrollo urbanístico de Salamanca en el siglo XX. Planes y proyectos en la organización de la ciudad, Valladolid, 2002, pp. 135-152.

${ }^{16} \mathrm{~V}$. de la ZARZA, “Intereses locales. Urbanización de la ciudad I", El Adelanto, 13-V-1937, p. 4.

${ }^{17}$ Según José Ignacio Díez Elcuaz, detrás del nombre de Vasco de la Zarza se encontraba Lorenzo González Iglesias. Los motivos por los que este investigador lo vincula son que, por un lado, este técnico era proclive a expresar en prensa sus opiniones en este ámbito $y$, por otro, que a través de sus textos se desprendía un conocimiento de la historia urbanística de la ciudad, del funcionamiento municipal, de la especulación urbana, de la legislación y de la terminología difícilmente alcanzable por un escritor o periodista no formado técnicamente. J. I. DÍEZ ELCUAZ, Arquitectura y urbanismo en Salamanca (1890-1939), Salamanca, 2003, p. 374. Véase V. de la ZARZA, "Intereses locales. Urbanización de la ciudad I", El Adelanto, 13-V-1937, p. 4; ÍDEM, “Intereses locales. Urbanización de la ciudad II", El Adelanto, 15-V-1937, p. 4; ÍDEM, "Intereses locales. Urbanización de la ciudad II", El Adelanto, 25-V-1937, p. 4; ÍDEM, "Intereses locales. Urbanización de la ciudad II", El Adelanto, 29-V1937, p. 4; ÍDEM, “Intereses locales. Urbanización de la ciudad I", El Adelanto, 4-VI-1937, p. 3; ÍDEM, “Intereses locales. Urbanización de la ciudad II", El Adelanto, 12VI-1937, p. 4. 
vienda y arquitecto de la sección de Urbanismo del Ayuntamiento de Salamanca.

\section{LAS ETAPAS DE LA OBRA DE LO- RENZO GONZÁLEZ IGLESIAS}

La carrera de González Iglesias consta de tres etapas. La primera se dilata desde 1935 hasta 1939 y se caracteriza por asumir el racionalismo como principal estilo. Esta corriente fue introducida en España por la Generación del 25, integrada por técnicos titulados en torno a esos años, quienes apostaron por una renovación en base a una ruptura formal con la tradición clásica, los revivales regionalistas y el eclecticismo imperante hasta entonces. A pesar de su espíritu de innovación, su labor estaba bastante alejada de la drástica revisión metodológica que implicaba el Movimiento Moderno, de manera que su aportación más notable consistió en la aplicación de este lenguaje con ciertos matices. Como avanzamos, la estancia del arquitecto abulense en Madrid indudablemente marcó esta inclinación. Hasta 1933, año en el que finalizó la carrera, pudo estudiar in situ inmuebles tan representativos como el cine Barceló (1930) de Luis Gutiérrez Soto, el edificio Capitol (1931), firmado por Vicente Eced Eced (1902-1978; titulado en 1927) y Luis Martínez-Feduchi Ruiz (1901-1975; titulado en 1927) o la colonia residencial El Viso (1933), de Rafael Bergamín Gutiérrez (18911970; titulado en 1918).

Por otro lado, también pudo acceder a estas referencias a través de las revistas Arquitectura y $A C$, que se convirtieron en el principal difusor de una estética moderna en España. En ella fueron publicados artículos de Fernando García Mercadal (18961985; titulado en 1921), Luis Lacasa Navarro (1899-1966; titulado en 1921) o Rafael Bergamín Gutiérrez (1891-1971; titulado en 1918), quienes desde el extranjero informaron de sus descubrimientos. Posteriormente, en sus páginas aparecieron muchos de los proyectos citados en estas líneas. No obstante, cabe señalar que la interpretación de este estilo por parte de González Iglesias fue similar a la de la mayoría de los arquitectos españoles, puesto que no llegó a cuajar obras puristas.

El panorama arquitectónico por aquel entonces en Salamanca ofrecía un amplio espectro en cuanto a repertorios formales, ya que se rastrean proyectos déco, tendencia que incidentalmente también se aprecia en algunas obras firmadas por el arquitecto que nos ocupa, y racionalistas. Además, se da la circunstancia de que los diseños más singulares se levantaron prácticamente en el mismo año en el que este facultativo finalizó sus estudios. Del primer estilo sobresalen las obras rubricadas por Genaro de No Hernández (1894-1978; titulado en 1918), autor del desaparecido teatro-cine Coliseum (1933), Eduardo Lozano Lardet (1897-1968; titulado en 1923), responsable de los planos del inmueble de Ana Mirat (1934), situado en la confluencia del paseo de Canalejas y la Gran Vía, y Ricardo Pérez Fernández (1894-1975; titulado en 1922). Este último fue el principal representante del art déco en la capital charra, motivo por el que la editorial Edarba publicó en 1935 una monografía sobre su aún incipiente obra ${ }^{18}$. El edificio de José Cordón (1932), situado en la calle San Pablo con vuelta a la de San Justo, y el de Cristino Romero (1932) en la Rúa son los mejores exponentes de esta corriente. Es probable que estos diseños los tuviese presente el arquitecto que nos ocupa para diseñar algunos de sus inmuebles, sobre todo a la hora de incluir determinados elementos ornamentales como en el remate de las fachadas y los antepechos de las ventanas y los balcones.

Por lo que atañe al racionalismo, cuando Lorenzo González Iglesias se asentó en Salamanca, ya se habían levantado importantes obras como la casa de vecindad de Luis Nodal Navarro (1933) en la calle Azafranal, concebida por Joaquín Secall Domingo (1881-1957, titulado en 1911), y la trascendental vivienda del catedrático de medicina Adolfo Núñez Rodríguez (1933) en la plaza del Liceo con vuelta a la calle Brocense, ru-

${ }^{18}$ I. COCO COCO, Arquitectura contemporánea en España. Ricardo Pérez, Madrid, 1935. 
bricada por Genaro de No, sin duda, el mejor exponente del racionalismo salmantino ${ }^{19}$.

En este contexto, a partir de 1935, proyectó sus primeras obras Lorenzo González. Según la documentación manejada, en esa fecha firmó unos cuarenta proyectos, cifra que corrobora, por un lado, la rápida inserción del técnico en el panorama constructivo de la ciudad y, por otro, la bonanza de la actividad edilicia que por aquel entonces atravesaba el país como consecuencia de la aplicación de medidas especiales para incentivar la construcción. Entre estas tuvo especial incidencia para el caso que nos ocupa la Ley de veinticinco de junio de 1935, conocida como Ley Salmón, denominada así en referencia al entonces ministro de Trabajo, Federico Salmón Amorío, quien implantó de nuevo el sistema de subvenciones y exenciones fiscales para la construcción de viviendas obreras y burguesas y, así, tratar de paliar el paro obrero.

La vivienda fue, con creces, la tipología más numerosa en la producción de González Iglesias. Cabe señalar al respecto que, como muchos de sus compañeros de profesión, la distribución espacial de sus obras resultó bastante convencional, dotadas, habitualmente, con una zona de servicio, de día y de noche claramente deslindadas.

19 A. GARCÍA BOÍZA, Arquitectura contemporánea en España. Genaro de No, Madrid, 1934, pp. 28-35; M. A. BALDELLOU SANTOLARIA y A. GONZÁLEZ-CAPITEL, Arquitectura Española del siglo XX, Madrid, 1995, p. 257; J. ALTÉS BUSTELO, Arquitectura moderna en Salamanca, Salamanca, 1998, p. 99; A. URRUTIA NÚÑEZ, Arquitectura española. Siglo XX, Madrid, 1997, p. 283; P. NÚÑEZ PAZ, P. REDERO GÓMEZ y J. VICENTE GARCIA, Salamanca. Guía de Arquitectura, Salamanca, 2001, pp. 164-165; J. I. DÍEZ ELCUAZ, Op. cit., pp. 422423; J. C. ARNUNCIO PASTOR, “La arquitectura desde 1930 hasta el siglo XXI", en J. R. NIETO GONZÁLEZ (coord.), Patrimonio arquitectónico de Castilla y León, Salamanca. 2007, pp. 33 y 42; M. GARCÍA FIGUEROLA, M. ORDÓÑEZ VICENTE, M. VIDAL GARCÍA y M. ZODER, Guía de Salamanca entre dos siglos (1870-1960), Salamanca, 2007, p. 65; M. CENTELLAS SOLER, C. JORDÁ SUCH y S. LANDROVE BOSSUT, La vivienda moderna, 1925-1965: Registro Docomomo Ibérico, Madrid, 2009, p. 121; E. AZOFRA AGUSTÍN y M. N. RUPÉREZ ALMAJANO, El arte en la Salamanca contemporánea, Salamanca, 2009, pp. 70-71.

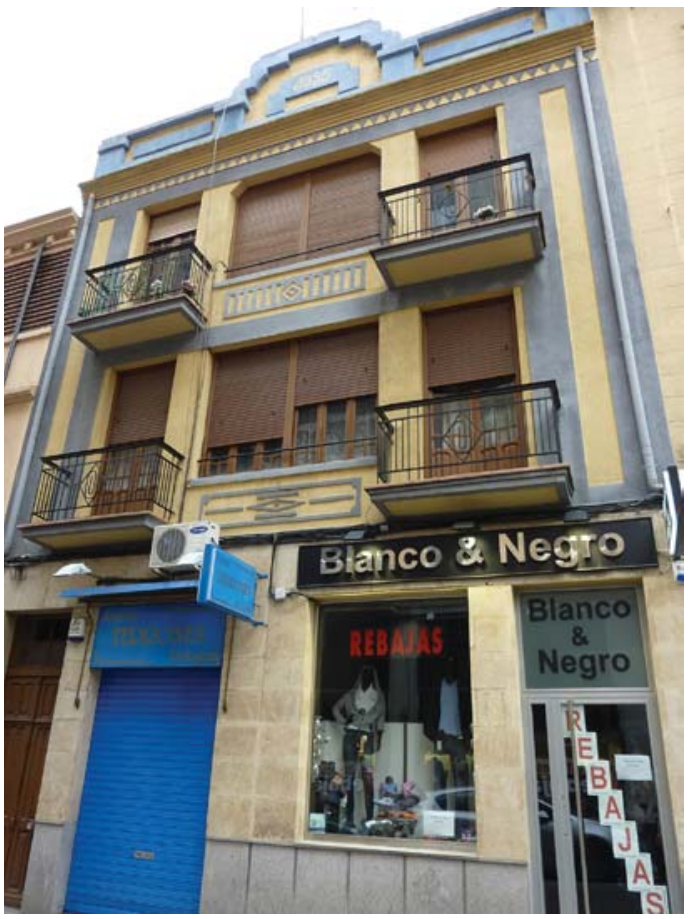

- Fig. 2. Fachada del edificio de Modesto Mulas (1935). Calle Pozo Amarillo. Foto del autor

Según la documentación hallada, la mayoría de los proyectos firmados en 1935 por el abulense fueron sencillas viviendas unifamiliares de una o dos plantas y, en menor número, casas de vecindad. Entre estas últimas sobresale la de Modesto Mulas (1935) en la calle Pozo Amarillo, que afortunadamente se conserva a fecha de hoy ${ }^{20}$ (Fig. 2). El Ayuntamiento aprobó en mayo de este mismo año los planos de este inmueble que consta de tres alturas, ordenadas en otros tantos ejes. González Iglesias configuró un frente donde incluyó detalles déco, tal como se aprecia en los motivos geométricos de los antepechos de las ventanas del cuerpo central y en la banda situada bajo la línea de imposta, la forja de los balcones de las calles extremas presidida por un diseño romboidal, las esquinas matadas del hueco central en el último piso y la peineta del remate donde consta el año de construcción del inmueble. El programa incluía en la planta baja locales comerciales y el portal, mientras que el resto de pisos albergaba una

\footnotetext{
${ }^{20}$ AMS, Fondo de obras, Caja 1751, Expediente 311
} 
vivienda por rellano, dotada con una sala de estar-comedor, tres dormitorios, una cocina y un WC.

No obstante, el paso hacia el racionalismo es palmario en el año 1936 y se prolongó hasta 1939, período en el que ejecutó algunos de los proyectos más singulares dentro de este estilo en la ciudad. En primera instancia señalamos el pabellón para salón de té que levantó en el jardín de la vivienda unifamiliar de Agustín Peña (1936), situada en la calle Azafranal, que no se conserva a fecha de hoy ${ }^{21}$. Llama la atención el uso de este inmueble, el único levantado con este cometido del que tenemos constancia. A esto se suma la calidad del proyecto, que dibujaba una planta de núcleo rectangular con un cuerpo semicircular adosado a uno de los lados largos, constaba de dos alturas y estaba presidido por formas desornamentadas, el vano continuo, la carpintería de tubo y la cubierta en terraza.

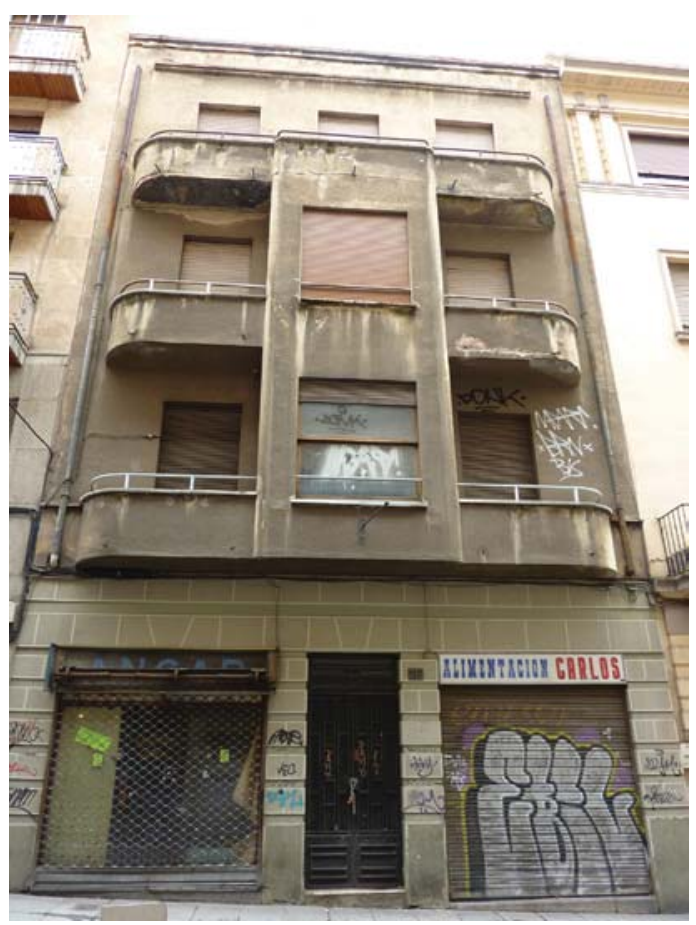

- Fig. 3. Fachada del edificio de Francisco Cañada (1936). Calle Pozo Amarillo. Foto del autor

\footnotetext{
${ }^{21}$ Ibídem, Fondo de obras, Caja 1753, Expediente 23.
}

Junto a éste, destaca el edificio de Francisco Cañada (1936) en la calle Pozo Amarillo $^{22}$ (Fig. 3). Ordenado en tres ejes y cuatro alturas, la configuración racionalista es evidente en la combinación volumétrica de los miradores de la calle central, de escaso vuelo, flanqueados por balcones, que subrayan los efectos de llenos y vacíos. La sobriedad y la desornamentación eran las notas características de este alzado. A estas últimas se sumaron el empleo de la carpintería de tubo y la solución redondeada de los extremos de los balcones, aunque en esta ocasión el artífice renunció a los huecos apaisados, que sí incluyó, por ejemplo, en la casa de vecindad de Francisco Sierra (1936), en la calle Antonio Espinosa, que no se conserva en la actualidad ${ }^{23}$.

Por lo que respecta al programa de la vivienda de Francisco Cañada en la planta baja dispuso el portal y dos locales comerciales, mientras que las restantes contaban con una vivienda por rellano, dotadas con dos dormitorios, una sala de estar, un comedor y un cuarto de baño.

Indudablemente el volumen de obras firmado en 1935 ratifica que en poco tiempo el técnico se hizo con una amplia cartera de clientes, lo que sin duda contribuyó a su asentamiento definitivo en Salamanca. De este modo, tan sólo un año después, en 1936, ideó uno de los proyectos que mayor expectación levantaron en su época en la ciudad: el frontón Tormes, situado entre la calle Vázquez Coronado y la plaza de San Boal. Este inmueble se levantó sobre el terreno desalojado por "unos corralones y unas casuchas viejas" ${ }^{24}$, pero, desafortunadamente, fue derribado en el año $2006^{25}$. Según la docu-

${ }^{22}$ Ibídem, Fondo de obras, Caja 1755, Expediente 207; J. I. DÍEZ ELCUAZ, Op. cit., p. 428.

${ }^{23}$ AMS, Fondo de obras, Caja 1754, Expediente 112.

24 J. SANCHÓN, Los Sánchez-Marcos: cincuenta años de cine en Salamanca, Salamanca, 1997, p. 21.

25 "Los Multicines Salamanca tendrán su última sesión el domingo a las ocho", La Gaceta Regional, 14-VI2006, p. 7; "Los Multicines Salamanca cierran después de 19 años", El Adelanto, 19-VI-2006, p. 10. 
mentación manejada, fue promovido por la sociedad mercantil integrada por el empresario Elpidio Sánchez Marcos y el delineante municipal Luis Nodal Navarro. Las trazas corresponden a González Iglesias, pero la dirección de la obra corrió a cargo del arquitecto salmantino Francisco Gil González (19051962; titulado en 1933), quien fue compañero de carrera del facultativo que nos ocupa ${ }^{26}$.

Hasta entonces existía en la ciudad el frontón descubierto de San Bernardo, emplazado en el paseo de San Vicente, sobre cuyo solar proyectó en 1945 Joaquín Secall (1881-1957; titulado en 1911) el edificio de viviendas de la Caja de Ahorros y Monte de Piedad de Salamanca ${ }^{27}$. No obstante, con la presente propuesta se apostaba por la puesta al día al incorporar una infraestructura cubierta, lo que favorecía la práctica del deporte de la pelota, que por aquel entonces gozó de gran aceptación. Buena muestra de esto es la proliferación de obras de este tipo por diferentes lugares de la geografía española, siendo representativos los madrileños frontones Jai Alai (1922), diseñado por Joaquín Otamendi Machimbarrena (1874-1960; titulado en 1900), situado en la calle Alfonso XI con vuelta a la de Valenzuela, que no se conserva en la actualidad; el Madrid (1929), firmado por Eduardo Lozano Lardet, en la calle Doctor Cortezo, que, a fecha de hoy ha sido convertido en un hotel, y el desaparecido Recoletos (1935), concebido por Secundino Zuazo Ugalde (1887-1971; titulado en 1912) en la calle Villanueva ${ }^{28}$. Probablemen-

${ }^{26}$ AMS, Fondo de obras, Caja 1755, Expediente 264; "Frontón Tormes, Salamanca", La Gaceta Regional, 18-I1938, p. 4; "Frontón Tormes, Salamanca", El Adelanto, 18-I-1938, p. 4. Sobre este arquitecto véase: S. NÚÑEZ IZQUIERDO, El arquitecto Francisco Gil González (19051962) y la arquitectura salmantina del segundo tercio del siglo XX, Tesis doctoral, Salamanca, 2014.

${ }^{27}$ AMS, Fondo de Obras, Caja 6281, Expediente 542; VV. AA., Guerra Civil y Radio Nacional: Salamanca 19361938, Madrid, 2006, pp. 96-97.

28 Véase al respecto J. GUTIÉRREZ MOSTEIRO, "Frontones en Madrid (1891-1936): singular tipo arquitectónico para la metrópoli", Ilustración de Madrid, $\mathrm{n}^{\mathrm{o}}$ 12,2009 , pp. 39-44. te, guiado por alguno de estos ejemplos, Lorenzo González Iglesias proyectó el frontón Tormes diseñado para el juego de la cesta punta, que exigía una cancha alargada con un muro al fondo, mientras que la gradería, los palcos y el "corredor, donde se presencia el espectáculo de pie" alojaban un aforo de menos de quinientos espectadores y estaban separados de la zona de juego por la contracancha ${ }^{29}$. El técnico abrió dos accesos orientados hacia las dos vías limítrofes. El inmueble constaba de cuatro alturas distribuidas en sótano, planta baja, principal y una más para los palcos. La primera albergaba el almacén, los vestuarios, la enfermería y el cuarto de calderas, mientras que en la baja estaba "el gran vestíbulo con una superficie más que suficiente, en relación con el número de espectadores que han de moverse en él" ${ }^{\prime 30}$, aparte del bar, las oficinas, la sede de la dirección y el guardarropa ${ }^{31}$. La planta principal estaba ocupada por la cancha de hormigón, la contracancha de madera y la gradería. Por último, estaba la parte de los trece palcos, que, según la memoria, tenían capacidad para sesenta espectadores.

Por lo que respecta al alzado, llama la atención que el técnico dejó constancia en la documentación de la voluntad de "conseguir que el edificio proyectado se adapte y no desentone del conocido palacio de San Boal y de la iglesia del mismo nombre, dándole una fachada de estilo semejante a la del palacio, a base de grandes arcos en la parte inferior y cubriendo el muro o fachadas con un esgrafiado análogo al que tiene dicho palacio, coronándolo con una cornisa de igual estilo y eligiendo como modelo una de las más vistosas o bellas que haya en el Salamanca antiguo" ${ }^{\prime 32}$. Sin embargo, a tenor de los planos hallados, la configuración final distaba notablemente de estos modelos (Fig. 4). Además, la fachada del frontón Tor-

\footnotetext{
${ }^{29}$ AMS, Fondo de Obras, Caja 1755, Expediente 264.

${ }^{30}$ Ibídem.

${ }^{31}$ Ibídem.

${ }^{32}$ Ibídem.
} 
mes se caracterizaba por el predominio del muro sobre el hueco, algo lógico en función del uso del mismo, pero, sorprendentemente, el artífice renunció a resolver la cubierta con una celosía metálica con lucernario en la parte central, como era habitual en edificios de este tipo. No obstante, el racionalismo del diseño era patente en la solución de la confluencia de las fachadas con un perfil redondeado, la ausencia de decoración, la cerrajería de tubo de hierro y el predominio de las líneas horizontales.

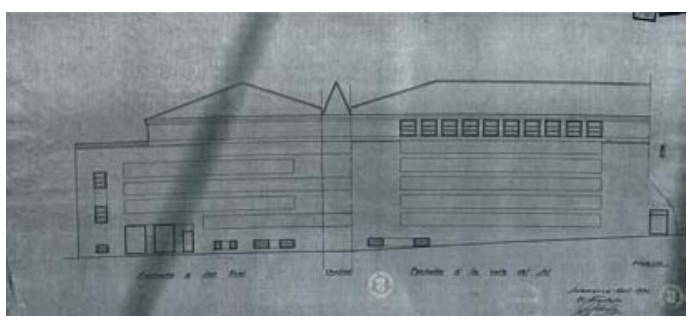

- Fig. 4. Alzado del frontón Tormes (1936). Calle Vázquez Coronado y Plaza de San Boal. Cedido por José Ignacio Díez Elcuaz

No obstante, los trabajos de construcción se prolongaron durante dos años, período en el que llegaron a estar paralizados durante casi uno, $\mathrm{y}$, finalmente, fue inaugurado en enero de $1938^{33}$. El edificio se empleó como tal hasta 1943. Un año después, Sánchez Marcos, a la sazón dueño único del inmueble, modificó el interior para convertirlo en viviendas y en un cine, el cinema Salamanca, adaptación que llevó a cabo el arquitecto Ricardo Pérez ${ }^{34}$.

Indudablemente, la relevancia de este encargo reportó una notable fama al técnico. Sin embargo, hasta 1939 González Iglesias diseñó muchos inmuebles modestos de una planta, en su mayor parte de viviendas, que forman parte de lo que hemos dado en

33 "Un obrero se cae desde seis metros de altura, en las obras de construcción del Frontón", El Adelanto, 18VI-1936, p. 8; "Frontón Tormes. Salamanca", La Gaceta Regional, 18-I-1938, p. 4; "Frontón Tormes. Salamanca", El Adelanto, 18-I-1938, p. 4.

${ }^{34}$ AMS, Fondo de obras, Caja 6242, Expediente 400 y Caja 6255, Expediente 511. llamar arquitectura desornamentada y cuyo programa respondía a las estancias mínimas propias de estas construcciones. Entre todas cabe señalar las situadas en las calles Conde de Cabarrús $^{35}$, Edisson ${ }^{36}$ y Alarcón ${ }^{37}$, que no se conservan a fecha de hoy.

\section{EL HISTORICISMO DE LA OBRA DE LORENZO GONZÁLEZ}

Tras el fin de la Guerra Civil el Nuevo Estado tuvo que hacer frente a la reconstrucción moral y material de la nación. Para ello renunció a enlazar estilísticamente con las corrientes imperantes durante la Segunda República, siguiendo el principio de que "a nueva política, nueva arquitectura" ${ }^{38}$, tal como sentenció Víctor d'Ors Pérez-Peix. Ante este panorama, los arquitectos que permanecieron en España se vieron obligados a renunciar a cualquier tipo de vanguardia y a llevar a cabo una labor de introspección sobre la tradición española en la búsqueda de las épocas gloriosas de la historia nacional, encontrando en el reinado de Felipe II y, en concreto, en el monasterio de El Escorial (Madrid) el modelo a seguir por su severidad, rigidez y geometrismo. Sin embargo, en el caso de Salamanca, coexistieron varias corrientes historicistas durante las primeras décadas del Franquismo. Algunas se inspiraban en ejemplos del pasado más glorioso de la arquitectura local, con especial incidencia del renacimiento, ya fuese en clave neoplateresca o más purista, así como el barroco, el clasicismo y, en menor medida, el gótico final y el neoclasicismo. En función de todo ello encontramos referencias aisladas a obras salmantinas como los palacios de

${ }^{35}$ Ibídem, Fondo de obras, Caja 1756, Expedientes 42, $43,45,48$ y $53-55$.

${ }^{36}$ Ibídem, Fondo de obras, Caja 1756, Expediente 79 y Caja 1758, Expedientes 80 y 85.

${ }^{37}$ Ibídem, Fondo de obras, Caja 1756, Expedientes 8, 10 y 11 .

${ }^{38}$ V. D'ORS PÉREZ PEIX, "Confesión de un arquitecto", F. E. Doctrina del Estado nacionalsindicalista, $\mathrm{N}^{\circ} 2$, 1938 , p. 3. 
Monterrey, Garcigrande y Orellana, la Catedral Nueva o la Plaza Mayor.

Así, en este contexto descollaron los proyectos firmados por Eduardo Lozano Lardet, Genaro de No Hernández, Ricardo Pérez Fernández y Francisco Gil González, entre otros. Este último técnico fue el que tuvo un mayor protagonismo por diseñar numerosas obras, en las que tuvo presente diferentes obras del renacimiento salmantino como los palacios de Monterrey, la Salina, Orellana, etc., cuyos detalles incorporó con gran libertad a muchos de sus diseños.

La segunda etapa de la producción de Lorenzo González, que abarca desde 1939 hasta 1955, está presidida por unos diseños de ineludible corte historicista. A diferencia de la mayoría de sus compañeros de profesión, Lorenzo González Iglesias se manifestó en contra de una excesiva carga decorativa y renunció a la copia de detalles ornamentales concretos de edificios históricos. Así, configuró soluciones que se caracterizan por la limpieza de los frentes divididos por marcadas líneas de imposta, huecos apenas recercados, la inclusión de piezas molduradas, que semejan la forma de dovelas o de ménsulas, colocadas normalmente en los entrepaños de las fachadas. Estas últimas pueden considerarse como identificativas de sus obras, así como los medallones y las esculturas de moderna factura.

No obstante, en la inmediata posguerra González Iglesias, al igual que muchos arquitectos en activo en la capital charra durante la preguerra y la guerra, continuó diseñando obras en las que se aprecia una continuidad con el racionalismo. Así se desprende de la casa de vecindad de María Pedraz López, situada entre las calles Pérez Oliva y Valencia, en cuyo alzado prescindió del uso de la piedra franca (Fig. 5) ${ }^{39}$. En agosto de 1939 el arquitecto que nos ocupa firmó los planos y tan sólo un mes más tarde el Ayun-

${ }^{39}$ Ibídem, Fondo de obras, Caja 1776, Expediente 549; J. I. DÍEZ ELCUAZ, Op. cit., pp. 458-459; S. NÚÑEZ IZQUIERDO, La tipologia..., pp. 524-525. tamiento aprobó la petición y comenzaron las obras. A fecha de hoy se conserva este edificio de seis alturas -la última en origen retranqueada, aunque posteriormente fue ampliada alterando la armonía de la fachada primitiva-, en el que el abulense apostó por el juego de volúmenes, enfatizado por el mirador de la esquina y la logia con capiteles jónicos del último piso, ambos sustentados por mensulones. Según José Ignacio Díez Elcuaz, la galería podría ser trasunto de soluciones populares sobre las que, como veremos más adelante, el arquitecto investigó y publicó algunos libros a lo largo de su vida. De todos modos, hay que aclarar que esta inspiración resultaba más evidente en el dibujo del alzado que en el resultado final, ya que fue modificado ligeramente durante su ejecución. Así, en un principio González Iglesias concibió unos huecos de medio punto en la planta baja, que fueron sustituidos por otros adintelados, salvo en el caso del correspondiente a la entrada al portal, $\mathrm{y}$, por el contrario, añadió pilastras de orden gigante en el cuerpo del mirador no incluidas en el diseño inicial.

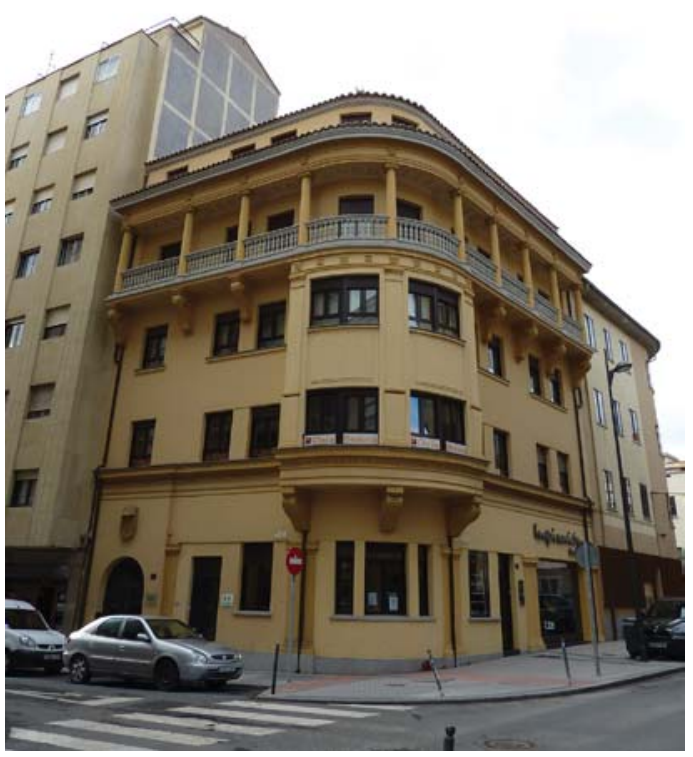

- Fig. 5. Fachada del edificio de María Pedraz López (1939). Calles Pérez Oliva y Valencia. Foto del autor 
Por lo que respecta al interior, el técnico proyectó un edificio con sótano, donde estaba el depósito del carbón; la planta baja se destinó a locales comerciales y al portal; las tres alturas restantes albergaban una vivienda por rellano y, por último, en el ático estaba la residencia del portero, que constaba de tres dormitorios, una cocina-comedor y un baño.

El acceso a las viviendas se realiza a través del hall, dependencia de la que el facultativo realizó un dibujo que incluyó en la documentación presentada. Díez Elcuaz también puso de manifiesto la influencia de lo popular en la solución del pavimento de lanchas, en el diseño de la consola de fábrica con resaltes de sillares y en las puertas con cuarterones de madera. Cada vivienda dispone de cuarto de estar, despacho, comedor -estos tres comunicados entre sí-, cuatro dormitorios -uno para la criada-, cocina con despensa, baño y lavadero con WC. La regularidad del solar facilitó ordenar las estancias en torno a un pasillo longitudinal, de manera que las dependencias principales rasgan sus huecos hacia las fachadas, mientras que las de servicio hacen lo propio hacia el patio de luces.

Centrados ya en algunas de las obras historicistas, cabe señalar la de Julián Sánchez Laso (1945), situada en la calle Concejo (Fig. 6) ${ }^{40}$. El inmueble que ocupaba el solar sobre el que se levantó el que nos ocupa quedó prácticamente derribado tras el bombardeo acaecido en la ciudad en enero de 1938. Ante los destrozos causados, el propietario decidió encargar un proyecto de nueva planta a Genaro de No, quien presentó los planos en mayo de 1940. Este arquitecto se decantó por una volumetría deudora en buena parte del racionalismo, pero, por motivos que desconocemos su propuesta nunca pasó de los planos. Así las cosas, el promotor retomó la iniciativa en diciembre de 1944, confiando en González Iglesias un nuevo diseño ${ }^{41}$. El so-

\footnotetext{
${ }^{40}$ AMS, Fondo de obras, Caja 6287, Expediente 84.

${ }^{41}$ Ibídem, S. NÚÑEZ IZQUIERDO, La tipología..., pp. 194-196.
}

lar medía 152 metros cuadrados, tenía forma rectangular y sobre él se levantó una casa de vecindad de cinco plantas. Las obras se retrasaron hasta septiembre de 1946, ya que se produjo un litigio entre Julián Sánchez Laso y Baltasar Moretón Martín, a la sazón dueño del inmueble colindante. El enfrentamiento se debió a la apropiación indebida por parte del primero de unos metros del patio de luces del segundo, resolviéndose la cuestión por vía judicial en la citada fecha.

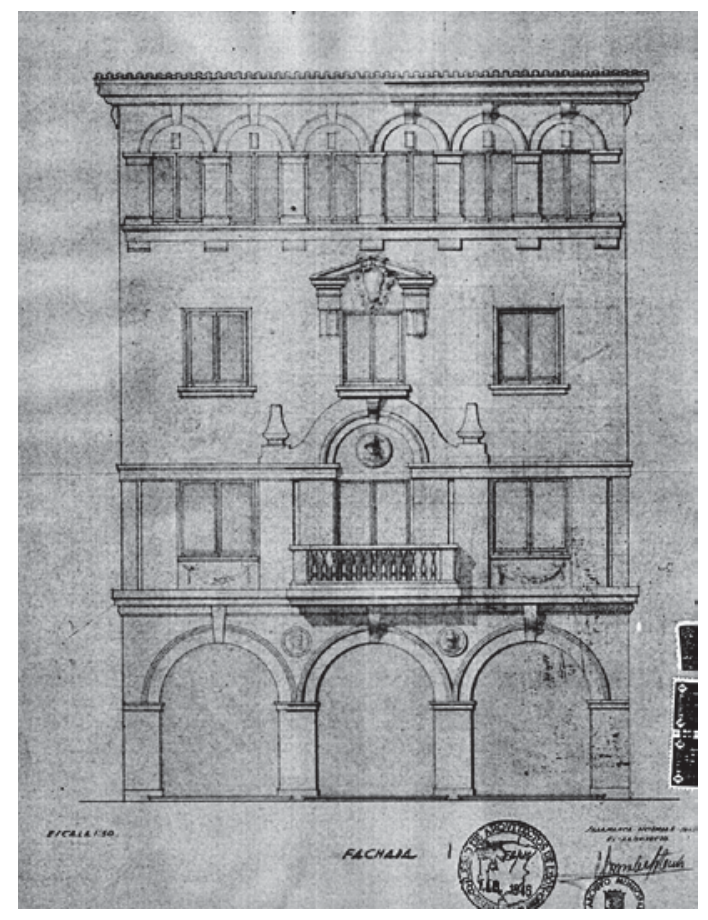

- Fig. 6. Alzado del edificio de Julián Sánchez Laso (1945). Calle Concejo. Cedido por José Ignacio Díez Elcuaz

Lorenzo González Iglesias concibió una fachada historicista condicionado por la cercanía a la Plaza Mayor y las modas en vigor por entonces. Las referencias al ágora son patentes en la solución de la planta baja, inspirada en sus galerías porticadas, con medallones en las enjutas, en este caso son dos y están decorados con los bustos de un hombre y de una mujer. Esta última está representada con una expresión de sufrimiento, algo palmario a través de la disposición de sus ojos y de su boca, desproporcionadamente abierta, de la que además 
sale una serpiente, mientras que el hombre aparece con rictus serio y triste. El reptil permite identificarlos como Adán y Eva, en concreto en el momento de la Tentación en el paraíso. En este sentido, hay que señalar que esta iconografía estaba presente en la portada del palacio renacentista de Rodríguez Figueroa, situado en la misma calle ${ }^{42}$. Otros detalles relacionan la fachada que nos ocupa con distintos inmuebles salmantinos, caso de la galería de arcos del último cuerpo, inspirada en la del palacio de Monterrey. Por lo demás, González Iglesias introdujo motivos ornamentales en sintonía con la tradición salmantina de los medallones, caso del existente en el eje central a la altura del primer piso, presidido por un hombre con las manos cruzadas, sosteniendo una máscara que parece burlarse del viandante. Esta pintoresca figura ha dado pie a diversas interpretaciones, entre ellas una que hace referencia al enfrentamiento entre los arquitectos González Iglesias y Gil González, autor del edificio situado en frente del que nos ocupa. En este sentido, el abulense criticó en algunas ocasiones el exceso de decoración de los diseños de su colega.

Por último, cabe destacar la estilizada solución de la forja, combinada con cristal, de la puerta original del zaguán, que en la actualidad no se conserva, pues era una buena pieza déco ${ }^{43}$. En el interior del portal el técnico decoró los nervios de las falsas bóvedas con molduras de escayola que imitan cabos anudados.

En cuanto a la distribución interior, la planta baja se destinó a locales comerciales, la primera a tres oficinas, mientras que las dos restantes albergan una vivienda por rellano y el ático la residencia del portero -con

${ }^{42}$ En este sentido véase VV. AA., Casino de Salamanca. Historia y Patrimonio, Salamanca, 2004, pp. 70 y 71. Otros autores identifican los personajes de estos medallones como Cleopatra y Marco Antonio. Véase M. GARCÍA FIGUEROLA, M. ORDÓÑEZ VICENTE, M. VIDAL GARCÍA y M. ZODER, Op. cit., p. 70.

${ }^{43}$ P. NÚÑEZ PAZ, P. REDERO GÓMEZ y J. VICENTE GARCIA, Op. cit., p. 149. comedor, cocina con despensa, dos dormitorios y un baño-. González Iglesias orientó hacia la fachada principal dos dormitorios y el comedor, mientras que relegó hacia los patios de luces el resto de dependencias, es decir, dos habitaciones y el cuarto de baño.

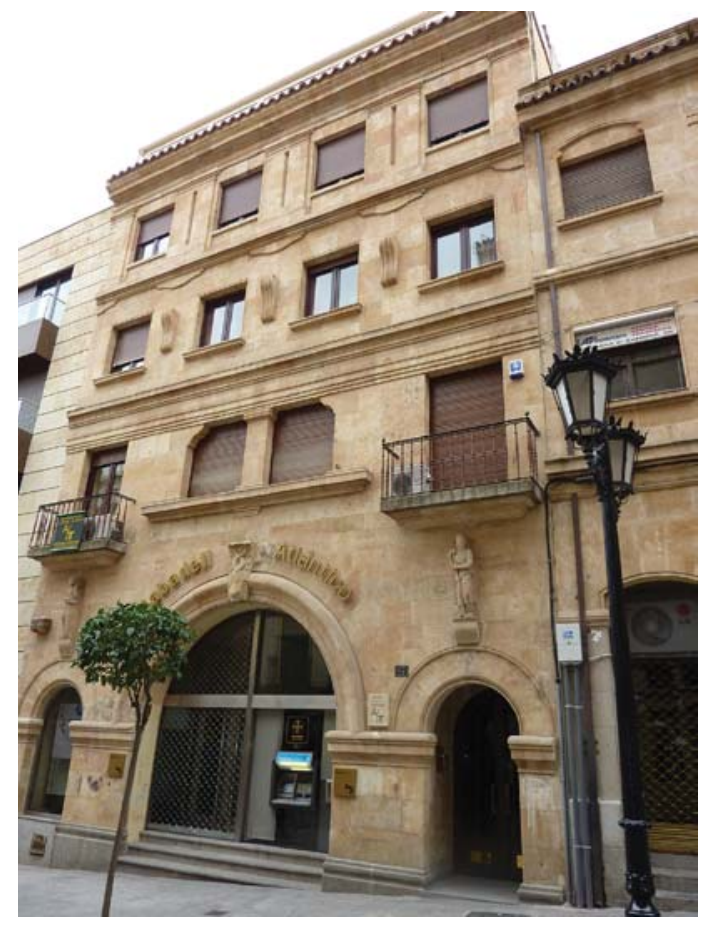

- Fig. 7. Fachada del edificio de Daniel Valle y José Sánchez (1946). Calle Vázquez Coronado. Foto del autor

Otro de los proyectos historicistas destacados de este arquitecto fue el inmueble de Daniel Valle y José Sánchez (1946) en la calle Vázquez Coronado (Fig. 7) ${ }^{44}$. Consta de cuatro alturas, estructurado en tres cuerpos, dándose el caso de que el bajo acoge dos plantas, de manera que adquiere un protagonismo poco usual. Cuenta con tres arcos de medio punto recercados, siendo de mayor tamaño el central, que remiten al juego existente en el pabellón consistorial de la Plaza Mayor. El hueco intermedio está aderezado con una clave esculpida. En ésta aparece un monstruo marino con dos extremidades en forma de aletas y piel de escamas, una cabeza

${ }^{44}$ AMS, Fondo de obras, Caja 6295, Expediente 492; S. NÚÑEZ IZQUIERDO, La tipología..., pp. 198-199. 
con dos orificios a modo de ojos, una enorme boca abierta y con potentes incisivos. Este animal está flanqueado por filacterias, con la leyenda BONUM y MALUM, sobre unas formas onduladas, de clara filiación déco, a través de las cuales su autor recreó las olas del mar. No tenemos constancia del artista responsable de esta pieza, aunque podría ser obra del escultor zamorano afincado en Salamanca José Luis Núñez Solé. Sorprende por su peculiar iconografía, aunque el hecho de que tenga dos extremidades podría ser una alusión al enfrentamiento de principios entre el bien y el mal.

Los vanos de las calles laterales están alineados con esculturas sobre ménsulas, labradas en piedra franca, que, según José Carlos Brasas Egido, datan de 1951, están firmadas por Núñez Solé y constituyen alegorías de El Arte y El Trabajo ${ }^{45}$. La primera es una figura femenina de cuerpo entero con la cabeza ligeramente inclinada y girada hacia el eje de la fachada. Digna de mención es la posición de sus brazos, uno rodeando por delante la cintura muestra la palma de la mano abierta hacia el espectador y el otro está alzado sustentando un objeto de difícil identificación, aunque, dado su significado, debía estar relacionado con el trabajo artístico. Los ropajes le cubren el cuerpo desde la cadera hasta los pies, mientras que el busto aparece completamente desnudo. El inconfundible estilo de su artífice se revela en el tratamiento de los paños con pliegues planos y secos bien geométricos o en zigzag, al igual que en la representación de las ondas del cabello.

Por lo que respecta a El Trabajo, Núñez Solé esculpió a un joven de pie con la cabeza girada en actitud de observación del horizonte. Por su caracterización resulta inmediato su reconocimiento, puesto que entre sus manos sostiene una azada en alusión a su quehacer habitual. En esta figura, como fue habitual en las obras de este artista, so-

${ }^{45} \mathrm{~J}$. C. BRASAS EGIDO, Núñez Solé: un escultor en la Salamanca de la posguerra, Salamanca, 2007, p. 163. bresale el tratamiento ciertamente minucioso del busto del hombre.

Aparte de estos detalles, destaca la segunda planta del inmueble por el hueco central geminado y mixtilíneo, flanqueado por dos balcones con antepechos de forja, sobre los que descansa una pronunciada moldura. En las dos alturas restantes cabe señalar la inserción de alargadas piezas estriadas en los entrepaños y placas recortadas en la línea de imposta.

El inmueble está edificado sobre un solar de forma trapezoidal de 167,76 metros cuadrados. La planta baja fue destinada a un local comercial de grandes dimensiones y considerable altura, que condicionó la ubicación del ingreso al portal en un extremo de la fachada y la propia composición del exterior del edificio. Los otros tres pisos albergaban una vivienda por rellano con la misma distribución. El arquitecto dispuso un amplio patio de luces central, que determinó la configuración de la planta en U y orientó hacia la fachada principal la sala de estar y dos dormitorios. Por el contrario, el resto de la zona de noche y de servicio tienen vanos abiertos hacia el citado patio.

A diferencia de lo que fue habitual en sus compañeros de profesión, realizó pocos proyectos para órdenes religiosas. Esto resulta llamativo en el caso de Salamanca, ya que fue una ciudad en la que, a partir de 1939, aumentaron notablemente el número de centros de enseñanza y seminarios religiosos, como consecuencia de la instauración de los estudios de Teología en la Universidad Pontificia. En este sentido, cabe decir que se ha llegado a hablar de la configuración de un "cinturón de incienso", pues muchos de esos edificios ocupaban las inmediaciones de la ronda de circunvalación abierta en torno a la antigua muralla o sus alrededores. Dentro de este panorama, Lorenzo González Iglesias rubricó las trazas del convento y colegio mayor de la Vera Cruz de los padres Mercedarios de la provincia de Castilla, cuyas obras promovió y donó en 1948 el industrial y banquero Andrés García Blanco, quien con 
anterioridad ya había confiado en el abulense algún proyecto, y su esposa, Laura Blanco Rodríguez-Vega ${ }^{46}$. Así, con esta obra, la orden religiosa regresó a nuestra ciudad, en la que ya estaba radicada desde el siglo $\mathrm{XV}$, en el Colegio de la Vera Cruz, que fue destruido en julio de 1812 al estallar el polvorín instalado en este inmueble durante la Guerra de la Independencia. Por otro lado, se este nuevo edificio permitió dotar al barrio de la Glorieta de un lugar donde oficiar actos religiosos, mientras que los propios promotores que vivían en las inmediaciones podían "llevar a cabo diariamente sus prácticas de piedad" 47 .

El inmueble concebido por González Iglesias está situado entre las avenidas de los Agustinos Recoletos y de la Merced, en un solar de 925 metros cuadrados, lindante con el chalet de estilo regionalista vasco, en el que fijó su residencia el benefactor, proyectado por el arquitecto Ricardo Pérez Fernández en 1940. El edificio conventual consta de sótano, planta baja y otras dos alturas. Del proyecto sobresale, por un lado, la capilla, cuyo acceso se orientó hacia la avenida de la Merced. Su alzado se caracteriza por la configuración a base de volúmenes rotundos con amplios lienzos de piedra arenisca, en los que el artífice prescindió de detalles decorativos. Estos últimos estaban concentrados en torno a los escasos huecos, así como la galería de arcos de medio punto de la última planta de gran modernidad al carecer de capiteles y molduras. Además, inicialmente el diseño preveía una torre en el testero del templo, rematada con un chapitel de ecos escurialenses en sintonía con las modas dicta-

${ }^{46}$ AMS, Fondo de obras, Caja 6353, Expediente 225; “El excelentísimo y reverendísimo señor obispo de la diócesis bendijo ayer la primera piedra del Colegio Mayor de la Vera Cruz. Fueron los padrinos los esposos don Andrés García Blanco y doña Laura Blanco R. Vega", El Adelanto, 9-III-1948, p. 6.

${ }^{47}$ Así lo indica Sol Olivera García, nieta de los benefactores, en las memorias publicadas sobre la fundación del inmueble. VV. AA., Cincuenta años de la Merced en Salamanca. Colegio Mayor de la Veracruz 1920-2000, Salamanca, 2000, p. 22 das por la oficialidad franquista, que nunca pasó de los planos (Fig. 8).

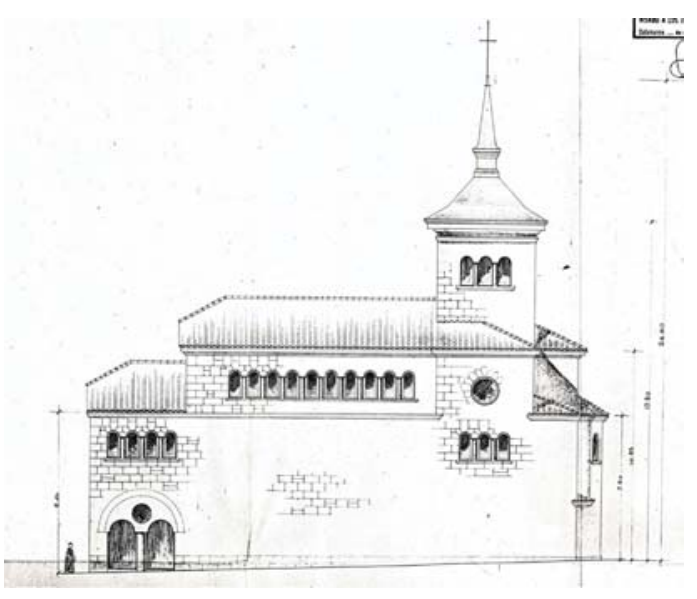

- Fig. 8. Alzado del convento y colegio mayor de la Vera Cruz de los padres Mercedarios de la provincia de Castilla (1948). Avenidas de los Agustinos Recoletos y de la Merced. Cedido por los padres Mercedarios

La planta de la iglesia dibuja una forma rectangular (Fig. 9). En el sótano está la cripta en la que están enterrados los miembros de la familia García Blanco, mientras que el piso bajo está ocupado por la capilla propiamente dicha, que consta de una única nave, inicialmente techada con un artesonado con casetones octogonales, que no se conserva en la actualidad. El presbiterio está precedido por unas gradas protegidas en un principio con un antepecho con balaustres, eliminado a fecha de hoy, y con tres arcos de medio punto a modo de iconostasis. El testero se ordena en tres ábsides con una bóveda de cañón el central y dos de crucería en los extremos (Fig. 10). El del medio está presidido por un retablo con copias de lienzos de Zurbarán y El Greco relativos a la Pasión y a la vida del fundador de la orden, en concreto: La aparición de San Pedro Apóstol a San Pedro Nolasco, La visión de San Pedro Nolasco, El Expolio, Cristo en la Cruz con María, Juan y María Magdalena y La Resurrección, y una talla de Nuestra Señora de la Merced. También son dignos de reseñar la galería de huecos de medio punto de pequeño tamaño, horadados en la parte alta de los lados largos de las naves, dotados con "vidrios historia- 
dos", término con el que González Iglesias se refirió a las vidrieras, en las que aparecen "los santos de la orden, los escudos de la misma, los Evangelistas y los fundadores de este nuevo Colegio Mayor" ${ }^{\prime 4}$, probablemente realizadas por la Casa Maumejean ${ }^{49}$.

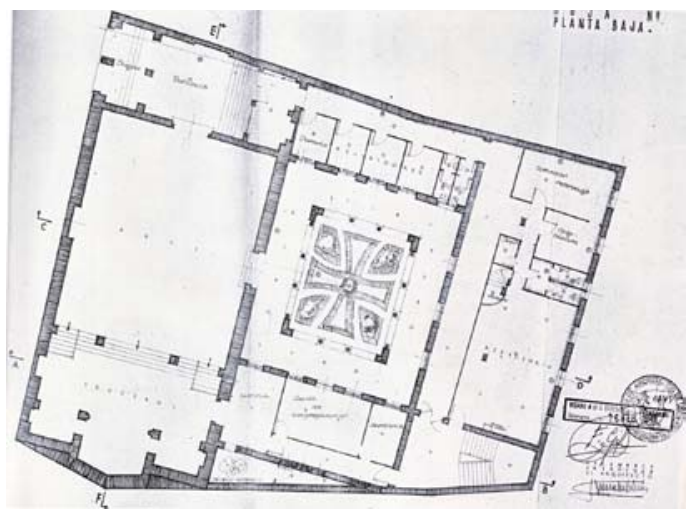

- Fig. 9. Planta baja del convento y colegio mayor de la Vera Cruz de los padres Mercedarios de la provincia de Castilla (1948). Avenidas de los Agustinos Recoletos y de la Merced. Cedida por los padres Mercedarios

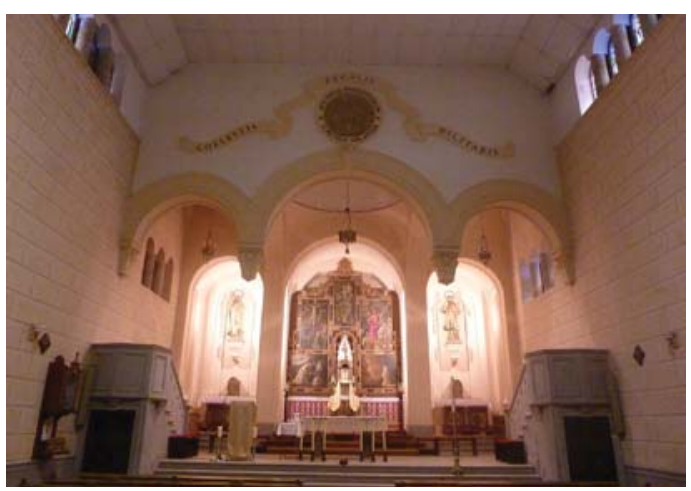

- Fig. 10. Capilla del convento y colegio mayor de la Vera Cruz de los padres Mercedarios de la provincia de Castilla (1948). Avenidas de los Agustinos Recoletos y de la Merced. Foto del autor.

${ }^{48}$ E. SALCEDO, “Un nuevo colegio mayor eclesiástico en Salamanca", La Gaceta Regional, 18-VI-1950, p. 5.

${ }^{49}$ Así se afirma en un artículo publicado en la prensa de la época rubricado por el periodista Emilio Salcedo, quien en varias ocasiones escribió textos en los que dejaba entrever su fundamentado criterio en cuestiones artísticas y arquitectónicas, sin embargo, no hemos hallado ningún documento ni la firma en las mismas que permita confirmarlo, aunque por su calidad es plausible esta adscripción.
A los pies de la capilla a la altura del primer piso están el coro y el antecoro, que, a su vez, comunican con las dependencias del claustro alto. El frente orientado hacia la capilla está resuelto con tres arcos escarzanos, sobre los que dispuso una franja decorada con guirnaldas presidida por un tondo con el escudo de la orden mercedaria, flanqueado por las esculturas de Jaime II y Esclaramunda de Mallorca, protectores de la Merced, efigies firmadas por el artista salmantino Agustín Casillas.

El programa incluía, además del templo, el resto de dependencias propias de un monasterio y colegio mayor, organizadas en torno al claustro lindante con la iglesia, que destaca por la incorporación de arcos de herradura de fábrica latericia. Por lo que atañe a la distribución, el sótano, además de la cripta de la capilla, estaba ocupado por la cocina, el almacén y los lavaderos. La planta baja albergaba el vestíbulo, la portería, la sala de visitas, la sala de congregaciones, la secretaría, el refectorio, los baños y el jardín, limítrofe con la avenida de los Agustinos Recoletos. El primer piso estaba ocupado por los aludidos coro y antecoro, además de la biblioteca, el vestuario y las celdas. Por último, en la segunda planta estaba la enfermería y el resto de dormitorios de la comunidad. Hay que señalar que la escalera que comunicaba con estas dependencias estaba situada en un extremo del pabellón orientado hacia el jardín.

La prensa salmantina se hizo eco de este proyecto, de cuya singularidad dio buena muestra González Iglesias, quien en una entrevista realizada por Emilio Salcedo en 1950 manifestó su voluntad de diseñar una residencia de religiosos, "pero a la medida humana, empleando el módulo humano" ${ }^{20}$. Así, el abulense demostró estar al día de las teorías más punteras en este ámbito arquitectónico y, en concreto, de la del módulo de Le Corbusier, publicada en 1948. Por entonces este preclaro arquitecto desarrolló un

50 "La orden de la Merced, vuelve a Salamanca", El Adelanto, 21-VI-1950, p. 4. 
sistema de medidas del cuerpo humano en el que cada magnitud se relaciona con la anterior en base al número aúreo.

Los rotativos locales también dejaron constancia de la evolución de las obras. El ocho de marzo de 1948 fue colocada la primera piedra, acto al que acudieron las principales autoridades civiles y religiosas de la ciudad ${ }^{51} \mathrm{y}$, en tan sólo dos años, el edificio fue inaugurado ${ }^{52}$.

\section{LOS AIRES RENOVADORES EN LA OBRA DE LORENZO GONZÁLEZ IGLESIAS}

La última etapa de la carrera proyectual de Lorenzo González abarca desde 1955 hasta 1964, año de su fallecimiento. Este período se caracterizó por un impulso modernizador en su obra con el diseño, entre otras cosas, de inmuebles de mayor altura, acorde con los nuevos vientos surgidos en la arquitectura española. En este sentido, cabe señalar que el panorama nacional asistió a partir del año 1949 a un cambio de mentalidad. En esta fecha los arquitectos se plantearon si el historicismo era el camino a seguir por la arquitectura española, dado lo que tenía de impuesto, anacrónico y ajeno a todo aquello que sucedía fuera de nuestras fronteras. Por aquellas fechas, el Boletín de la Dirección General de Arquitectura y la Revista Nacional de Arquitectura, editada por el Colegio Oficial de Arquitectos de Madrid, publicaron

51 "El excelentísimo señor obispo de la diócesis bendijo ayer la primera piedra del colegio mayor de la Vera Cruz", El Adelanto, 9-III-1948, p. 1.

52 “Un nuevo Colegio Mayor Eclesiástico en Salamanca", La Gaceta Regional, 18-VI-1950, p. 5; E. SALCEDO, "La orden de la Merced, vuelve a Salamanca", El Adelanto, 21-VI-1950, p. 4; "Ayer fue inaugurado el Colegio Mayor de la Vera Cruz", La Gaceta Regional, 22VI-1950, p. 4; "Inauguración en Salamanca del Colegio Mayor de la Vera Cruz", $A B C, 22-V I-1950$, p. 22; "Inauguración del Colegio Mayor de la Vera Cruz de PP. Mercedarios. Fue presidida por el Nuncio de Su Santidad, en Salamanca", La Vanguardia Española, 22-VI-1950, p. 4; "Solemne bendición e inauguración de la iglesia y convento-residencia de profesores del Colegio Mayor de la Vera-Cruz", El Adelanto, 22-VI-1950, p. 1. artículos en los que se reflejaba una cierta desorientación y, por ende, el creciente escepticismo.

Este viraje también estuvo favorecido, en el caso de Salamanca, por la modificación de las ordenanzas municipales en 1958. La nueva normativa, a diferencia de lo marcado hasta la fecha, eximía de la obligatoriedad de uso de la piedra de Villamayor en las fachadas, permitiendo el ladrillo cara vista, además de la potenciación de la incorporación de los balcones corridos. Esto, unido a una manifiesta ausencia de decoración, se aprecia en algunas obras como la clínica de Antonio Ferreira (1955) en la calle Corrales de Monroy ${ }^{53}$, la casa de vecindad de Andrés Corrionero (1958) en la avenida de Mirat ${ }^{54}$ (Fig. 11), la de Marcelina Rodríguez (1962) en la avenida de Filiberto Villalobos ${ }^{55}$ y la de Alfredo Martín-Cubas (1963) en el paseo del doctor Torres Villarroel ${ }^{56}$, entre otras.

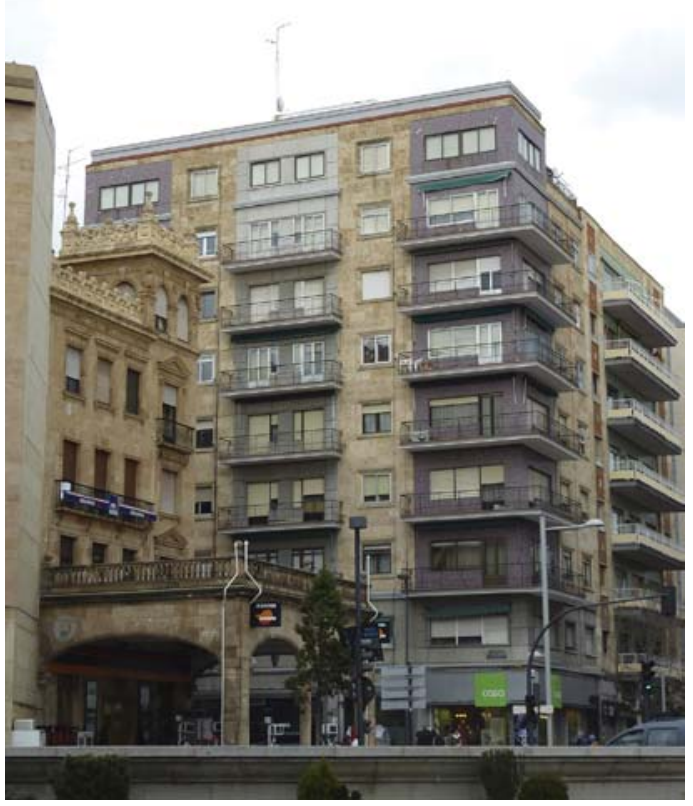

- Fig. 11. Fachada del edificio de Andrés Corrionero (1958). Avenida de Mirat. Foto del autor

\footnotetext{
${ }^{53}$ AMS, Fondo de obras, Caja 6213, Expediente 268.

${ }^{54}$ Ibídem, Fondo de obras, Caja 6486, Expediente 452.

${ }^{55}$ Ibídem, Fondo de obras, Caja 6564, Expediente 333 y Caja 6615, Expediente 462.

${ }^{56}$ Ibídem, Fondo de obras, Caja 6619, Expediente 231.
} 
LORENZO GONZÁLEZ IGLESIAS, ARQUITECTO VINCULADO A LA ADMINISTRACIÓN

Todo lo dicho hasta ahora corresponde al desempeño libre de la profesión de arquitecto, pero otra de las facetas de Lorenzo González es la relativa a los puestos que desempeñó al servicio de la administración, que pudo simultanear con la práctica liberal de la arquitectura. La primera noticia al respecto data de febrero del año 1938, fecha en la que fue nombrado arquitecto provisional de la Diputación. Desempeñó este cargo por expresa recomendación del técnico titular de la misma, el madrileño Eduardo Lozano Lardet, quien en ese momento, difícilmente podía compaginar este puesto con los servicios que por entonces desempeñaba en la Jefatura Nacional de Beneficencia y Obras Sociales, tarea que además le obligaba a viajar al extranjero con frecuencia ${ }^{57}$. De este modo, González Iglesias intervino en la proyección de un sótano en el hospital Provincial, inmueble diseñado por el propio Lozano en 1926, así como en las obras de reforma y adaptación del edificio de Llano Alto de Béjar (Salamanca) para convertirlo en sanatorio antituberculoso y en los trabajos del asilo de incurables de Ciudad Rodrigo (Salamanca) ${ }^{58}$. Sin embargo, ocho meses después, en noviembre de 1938, González Iglesias fue reclutado para luchar en el frente bélico, al decretarse "la movilización y llamamiento a filas de los individuos pertenecientes al reemplazamiento de 1927"59, donde permaneció hasta el mes de mayo de 1939.

A su regreso a Salamanca, la Diputación le ofreció su antiguo puesto, visto que Lozano Lardet no podía atender de manera continuada sus obligaciones en la institución

${ }^{57}$ Archivo de la Diputación Provincial de Salamanca (en adelante ADPS), Libro no ${ }^{-183}$. Actas de la Comisión Gestora. Sesión del 28 de febrero de 1938, fol. 96.

${ }^{58}$ Ibídem, Libro no ${ }^{-185}$. Actas de la Comisión Gestora. Sesión del 16 de marzo de 1940, fol. 100.

${ }^{59}$ Ibídem, Libro no 183. Actas de la Comisión Gestora. Sesión del 28 de noviembre de 1938, fol. 374 v. provincial por la imposibilidad de compaginarlas con sus numerosas responsabilidades al servicio de organismos estatales, como fiscal delegado de la Vivienda ${ }^{60}$, representante de la Dirección General de Arquitectura y miembro de la Comisión Superior de Ordenación Urbana de la provincia de Salamanca $^{61}$, que le obligaban a ausentarse de la ciudad durante largas temporadas ${ }^{62}$. Así las cosas, González Iglesias desempeñó el cargo durante un año, hasta el quince de mayo de 1940, fecha en la que el titular del mismo regresó a la capital charra para ocupar de nuevo su cometido como arquitecto provincial $^{63}$. Esta nueva situación acabó provocando enfrentamientos entre ambos técnicos, porque la Diputación solicitó ulteriormente la colaboración ocasional del abulense, a lo que se negó Lozano Lardet. Finalmente, la Corporación Provincial concedió a Lorenzo González un "despacho separado en el que pudiese trabajar con absoluta independencia e intervenir junto al titular en los anteproyectos de los nuevos edificios de la Beneficencia Provincial" ${ }^{\prime 64}$. En consonancia con este acuerdo, fue el responsable de las obras de reforma llevadas a cabo en los edificios provinciales, mientras que el madrileño fue el artífice de los de nueva planta ${ }^{65}$. Esta situación solventó temporalmente la actividad constructiva de la Diputación, aunque, finalmente, en julio de 1941 González Iglesias presentó su dimisión.

60 "Las fiscalías de la vivienda", El Adelanto, 28-XII1940, p. 4; "Nuevo Fiscal de la Vivienda", La Gaceta Regional, 4-XII-1940, p. 2; "Nuevo fiscal delegado de la Vivienda", El Adelanto, 4-XII-1940, p. 4.

${ }_{61}$ "Se constituye la Comisión Superior de Ordenación Urbana de la provincia de Salamanca", La Gaceta Regional, 30-I-1953, p. 1; "Se constituye la Comisión Superior de Ordenación Urbana de la provincia de Salamanca", El Adelanto, 30-I-1953, p. 1.

${ }^{62}$ ADPS, Libro no 184 . Actas de la Comisión Gestora. Sesión del 29 de mayo de 1939, fol. $131 \mathrm{v}$.

${ }^{63}$ Ibídem, Libro no 185. Actas de la Comisión Gestora. Sesión del 20 de mayo de 1940, fol. 200.

${ }^{64} \mathrm{Ibídem}$. Sesión del 1 de julio de 1940, fol. 227.

${ }^{65}$ Ibídem, Libro no 186. Actas de la Comisión Gestora. Sesión del 24 de marzo de 1941, fol. 94 v. 
En 1945 nuestro protagonista fue nombrado técnico delegado provincial del Instituto Nacional de la Vivienda, cuyo desempeño consistió, principalmente, en asesorar técnicamente en el diseño de proyectos de nueva planta ${ }^{66}$. Cinco años después, el hasta entonces arquitecto municipal responsable de la sección de Urbanismo, Fernando Población del Castillo (1917-2002; titulado en 1947), dimitió de su cargo, ocasión que fue aprovechada por González Iglesias para presentar su candidatura, lo que fue visto con buenos ojos por el Consistorio, dada "la relación de méritos que justifica el solicitante y la reconocida solvencia profesional y de salmantinismo que le es conocida" ${ }^{\prime 67}$. Esta oportunidad le sirvió para poder presentar su candidatura como titular para la plaza de segundo arquitecto del Ayuntamiento en noviembre de 1953. El tribunal de esta oposición estuvo presidio por Carlos Gutiérrez de Ceballos e integrado por arquitectos relevantes del panorama local y nacional ${ }^{68}$. Entre ellos cabe destacar al mentado a Francisco Gil, quien no estuvo presente en la elección por ausentarse ese día de Salamanca, Rafael Fernández-Huidobro Pineda (1908-1994; titulado en 1933), quien asistió en calidad de subdirector de la Escuela Superior de Arquitectura de Madrid, Ricardo Pérez Fernández, como arquitecto municipal, y Rodolfo GarcíaPablos y González Quijano (1914-2001; titulado en 1940$)^{69}$, representante de la Dirección

${ }^{66}$ AMS, Libro no 337. Actas del Pleno del Ayuntamiento. Sesión del 29 de septiembre de 1944, fol. 14 v.; Ibídem, Fondo de obras, Caja 6376, Expediente 191.

${ }^{67}$ Ibídem, Libro no 350. Actas del Pleno del Ayuntamiento. Sesión del 5 de mayo de 1950, fol. 202 v.

${ }^{68}$ González Iglesias admiró la labor desempeñada por el entonces alcalde Carlos Gutiérrez de Ceballos. De hecho, en una entrevista manifestó que era la única persona capaz de transformar y revalorizar Salamanca por completo, ya que "nadie mejor que yo conoce la constante preocupación del alcalde por la ciudad y la perfecta visión que tiene de todos los problemas para resolverlos". SANT-YAGO, "Al habla con... González Iglesias", El Adelanto, 2-VI-1954, p. 4.

${ }^{69}$ Estos datos proceden de la esquela aparecida en $A B C, 4-\mathrm{I}-2001$, p. 71.
General de Arquitectura. Los cinco candidatos fueron Ramón González de Vega y Soto (nacido en 1913; titulado en 1944), Fernando Alcántara Montalvo (fallecido en 1964; titulado en 1922), Francisco Alonso San Millán (nacido en 1911; titulado en 1943), Amando Diego Vecino (1921-1992; titulado en 1951) y el técnico que nos ocupa ${ }^{70}$. Tras una valoración de sus trayectorias profesionales decidieron calificar de manera unánime con la máxima nota a Lorenzo González Iglesias. Gran parte del desempeño de su cargo consistió en supervisar las licencias de obras de inmuebles de nueva planta, la modificación de los usos de los terrenos, la urbanización de numerosas vías del centro de la capital y la erradicación de las viviendas construidas de manera ilegal en varias zonas alejadas de los límites del ensanche ${ }^{71}$. Este problema era tan acuciante que en 1951 el propio González Iglesias llegó a proponer la configuración de un prototipo genérico de viviendas modestas susceptible de ser materializado mediante la autoconstrucción por parte de los propios promotores, bajo la supervisión de un técnico, siempre y cuando sus propietarios cumpliesen unos requisitos legales. No obstante, la iniciativa nunca pasó de los planos.

De todas sus actuaciones al servicio del Ayuntamiento destaca la eliminación de los parterres, que hasta 1954 ocupaban el centro de la Plaza Mayor, que el abulense sustituyó por el enlosado de piedra granítica, que subsiste hoy en día. Esta medida tuvo por objeto unificar el nivel de pavimentación de todo el ágora y, así, eliminar todo aquello que supusiese un obstáculo para la contemplación del monumento barroco ${ }^{72}$.

${ }^{70}$ AMS, Libro no 356 . Actas del Pleno del Ayuntamiento. Sesión del 10 de diciembre de 1953, fol. 355 v.

${ }^{71}$ Ibídem, Fondo de obras, Caja 6396/1, Expediente 26.

72 Ibídem. Libro no 358. Actas del Pleno del Ayuntamiento. Sesión del 7 de enero de 1954, fols. 9, 19, 148 y 184.; A. RODRÍGUEZ GUTIÉRREZ de CEBALLOS, La Plaza Mayor de Salamanca, Salamanca, 1977, p. 184; D. SENABRE LÓPEZ, "La Plaza Mayor de Salamanca en el urbanismo del siglo XX". Ciudades: revista del Instituto Universitario de Urbanística de la Universidad de Valladolid, nº 11, 2008, pp. 199-200; S. NÚÑEZ IZQUIERDO, "Las 
Tres años en el Ayuntamiento fueron suficientes para que Iglesias demostrase su eficacia, de manera que en 1956 fue nombrado arquitecto jefe de la sección de Urbanismo. En 1961 dimitió del cargo, quizá motivado por cuestiones de salud, pero no renunció al ejercicio libre de la profesión ${ }^{73}$. Tras su marcha, el Consistorio convocó un concurso de méritos al que concurrieron Amando Diego Vecino, Ricardo Pérez Rodríguez-Navas y, el técnico seleccionado, Antonio García Lozano ${ }^{74}$.

\section{LORENZO GONZÁLEZ IGLESIAS, AVEZADO COLUMNISTA Y ESCRI- TOR}

González Iglesias dejó constancia de sus opiniones en materia de arquitectura a través de los artículos que publicó en La Gaceta Regional entre 1950 y 1951, que fueron recopilados en el libro Ensayos sobre urbanismo salmantino, editado el último de estos años ${ }^{75}$. Estos textos son un testimonio del pensamiento arquitectónico y artístico de este arquitecto, quien plasmó de manera socarrona, mordaz y clarividente sus opiniones. En este sentido, resulta revelador el titulado "Mimetismo urbano", donde denunció que "las nuevas construcciones que se levantan en el interior de nuestra ciudad van taradas de arqueologismo, balbucientes de renacentismo y lamentable competencia con los edificios antiguos (...) sin bucear el módulo"76. Sólo en el ensanche,

intervenciones en el patrimonio monumental de Salamanca. El Servicio de Defensa del Patrimonio Artístico Nacional según la documentación hallada en el Archivo Municipal de Salamanca", en A. COLORADO CASTELLARY (ed.), Patrimonio, Guerra Civil y Posguerra. Congreso Internacional, Madrid, 2010, p. 293.

${ }^{73}$ AMS, Libro no 372. Actas del Pleno del Ayuntamiento. Sesión del 9 de marzo de 1961, fol. $89 \mathrm{v}$.

${ }^{74}$ Ibídem, Libro $\mathrm{n}^{\mathrm{o}}$ 372. Actas del Pleno del Ayuntamiento. Sesión del 16 de septiembre de 1961, fol. 241.

${ }^{75}$ L. GONZÁLEZ IGLESIAS, Ensayos sobre urbanismo salmantino. Una campaña de La Gaceta Regional, Salamanca, 1951.

76 ÍDEM, "Mimetismo urbano", La Gaceta Regional, 7-VIII-1950, p. 6. alejado del centro de la ciudad, "se permitiese y provocase toda clase de instintos creacionistas"77. $^{17}$.

Una de las reseñas más elocuentes fue "Medio siglo de progreso urbano", firmada en 1950, en la que acertadamente esbozó el crecimiento de la ciudad, en el que incluso aseguraba que "la arquitectura salmantina no se ha encontrado a sí misma ni es de suponer se encuentre en el futuro siguiendo el rumbo que lleva. La variedad estilística de sus antiguos monumentos y la personalidad acusada de cada uno de ellos, da a la ciudad antigua una variedad muy agradable para los ojos del turista, pero produce indecisión en los encargados de crear obra nueva. Y si a esto se añade el equivocado concepto de tomar por obra arquitectónica la repetición de detalles decorativos de tipo antiguo, ejecutados por las inexpertas manos actuales, entonces la equivocación culmina y la auténtica ruta se ha perdido definitivamente. Las torres y cresterías de Monterrey, acaso justificadas en su época, los soportales de la Plaza, justificados siempre por estar en el centro vital ciudadano, la edificación pétrea antigua exornada en barroco, no deben constituir pies forzados para la construcción nueva, levantando cresterías en serie, aporticando calles que no necesitan de ello ni adornando con alcachofas barrocas o insulsos barandales de balcón, fachadas de composición aún más insulsas". Estas palabras ratifican claramente que su ojo calibró perfectamente los puntos de inspiración de sus compañeros, así como los elementos consustanciales a la arquitectura historicista y su más absoluta desaprobación. En este sentido, como ya avanzamos, el enfrentamiento con Francisco Gil fue directo por la predilección del último por adornar las fachadas de sus edificios con las composiciones y los motivos de los edificios del patrimonio renacentista y barroco de la ciudad.

77 "Dos arquitectos y un aparejador responden a cinco preguntas", La Gaceta Regional, 18-VII-1963, p. 12. 
González Iglesias tildó a la arquitectura salmantina de la década de los cuarenta y cincuenta como "un agrisado término medio que, con el tiempo, hará aumentar el carácter y la personalidad de la ciudad antigua" 78 .

Como experto urbanista atinó en su previsión del desarrollo alcanzado en Salamanca para el año $2000^{79}$, predicción que vaticinó en una entrevista en el año 1963, en la que aseveró que "la ciudad antigua continuaría terne y derecha. La ciudad circundante, sin embargo, aparecerá deslucida e impersonal" ${ }^{\prime 80}$.

En sus artículos el arquitecto también trató asuntos como los parques ${ }^{81}$, el barrio obrero de los Pizarrales ${ }^{82}$, la construcción de viviendas en el extrarradio ${ }^{83}$, el nuevo barrio El Conejal ${ }^{84}$, los proyectos arquitectónicos truncados ${ }^{85}$, así como muchos rincones y edificios significativos de la capital charra como las plazas del Aire ${ }^{86}$ y de los Bandos ${ }^{87}$, la calle de San Julián ${ }^{88}$, la puerta de Zamo-

${ }^{78}$ Ibídem.

${ }^{79}$ L. GONZÁLEZ IGLESIAS, “Medio Siglo de Progreso Urbano", La Gaceta Regional, 1-I-1950, p. 4.

80 "Dos arquitectos y un aparejador responden a cinco preguntas", La Gaceta Regional, 18-VII-1963, p. 12.

${ }^{81}$ L. GONZÁLEZ IGLESIAS, “El nuevo Parque y la higiene”, La Gaceta Regional, 26-II-1950, p. 5.

82 ÍDEM, "A mitad del camino", La Gaceta Regional, 14-IV-1950, p. 4.

83 ÍDEM, "Mimetismo urbano", La Gaceta Regional, 7-VIII-1950, p. 6.

${ }^{84}$ ÍDEM, "El Conejal, el barrio más céntrico y su reforma”, La Gaceta Regional, 19-XI-1950, p. 4; ÍDEM, “El proyecto del Barrio de San Juan de Sahagún. Se realizará por los sistemas de compensación y cooperación que autoriza la Ley del Suelo", La Gaceta Regional, 20VII-1958, p. 3.

${ }^{85}$ ÍDEM, "Paisaje urbano", La Gaceta Regional, 17-IX1950, p. 3.

86 ÍDEM, "La plaza del Aire", La Gaceta Regional, 8-X-1950, p. 3.

87 ÍDEM, “La plaza de los Bandos”, La Gaceta Regional, 15-X-1950, p. 5.

${ }^{88}$ ÍDEM, "La calle de San Julián", La Gaceta Regional, 23-X-1950, p. 6. $\mathrm{ra}^{89}$, la iglesia de San Juan de Barbalos ${ }^{90}$, la puerta de Toro $^{91}$, la catedral ${ }^{92}$, el futuro de la ciudad $^{93}$ y el barrio antiguo ${ }^{94}$.

Otra de las cuestiones que preocupaban a González Iglesias era la relativa a la ordenación de las ciudades como Salamanca, en las que tenía un gran peso el conjunto monumental. Durante sus años como técnico municipal "observó las interferencias y fricciones producidas entre los encargados de velar por la conservación de algunos conjuntos monumentales y pintorescos y los habitantes de éstos ${ }^{\prime \prime 5}$. De este modo, abordó la cuestión con el objeto de lograr "los procedimientos más eficaces para suavizarlos. A su modo de ver, lo más adecuado era una ordenanza adecuada para lograr una ciudad viviente y activa y, por lo tanto, con derecho natural a no ser momificadas" ${ }^{\prime \prime 6}$. En este sentido, el abulense recomendó elaborar un estudio preparatorio del estado de la cuestión en el que interviniesen profesionales como topógrafos, arqueólogos, historiadores, fotógrafos, aparejadores y arquitectos, quienes diseñarían un plan general de la ciudad. Este último debía incluir una parte detallada del ensanche, así como una exhaustiva documentación fotográfica de cada fachada significativa del patrimonio arquitectónico. En base a ese completo archivo, se redactarían las ordenanzas con una clasificación de los

89 ÍDEM, "Puerta de Zamora", La Gaceta Regional, 28-X-1950, p. 4.

${ }^{90}$ ÍDEM, "San Juan de Barbalos", La Gaceta Regional, 5-XI-1950, p. 3.

${ }^{91}$ ÍDEM, "La puerta de Toro y sus problemas de circulación", La Gaceta Regional, 12-XI-1950, p. 3.

92 ÍDEM, "A los pies de la Catedral", La Gaceta Regional, 16-XI-1950, p. 3.

93 ÍDEM, "La ciudad al correr del tiempo", La Gaceta Regional, 31-XII-1950, p. 4.

${ }^{94}$ ÍDEM, "El Barrio Viejo Salmantino. IV", La Gaceta Regional, 16-X-1951, p. 3.

95 ÍDEM Ciudades y conjuntos monumentales. Avance para un estudio de ordenación estética, Salamanca, 1951, p. 5.

${ }^{96}$ Ibídem. 
edificios según la escala y los valores que se apreciasen en su diseño, tanto los de tipo histórico, arqueológico, pintoresco, pseudotípico, como los que fueran una "intrusión en el ambiente" ${ }^{\prime 97}$.

\section{GONZÁLEZ IGLESIAS Y LA SIERRA DE FRANCIA (SALAMANCA)}

A lo largo de su vida, Lorenzo González Iglesias dio muestras de una gran sensibilidad por las cuestiones artísticas y etnográficas. En base a esto, trató de profundizar en algunos temas que fueron de su interés auspiciado por entidades tan relevantes como el Instituto Nacional de la Vivienda y la Real Academia de Bellas Artes de San Fernando. De hecho, el rigor de sus investigaciones propició su dimisión como arquitecto provincial en el mes de julio de 1941, fecha en la que su proyecto sobre la localidad extremeña de Las Hurdes fue seleccionado concediéndosele la pensión de Arquitectura de la Fundación benéfico-docente Conde de Cartagena ${ }^{98}$.

La comarca de la Sierra de Francia (Salamanca) y, en concreto, la localidad de La Alberca fue otro de los parajes que centraron su atención, hasta el punto de llegar a considerarla como "el centro de España más completo en arte. Allí podemos encontrar motivos de pintura, escultura, grabado, arquitectura, música, baile, bordado, artesanía" ${ }^{\prime 99}$. Reflejo de este sentir, en 1954 Iglesias obtuvo la tercera medalla en la Exposición Nacional de Bellas Artes por un dibujo de una residencia para artistas en La Alberca (Salamanca), para la que configuró un alzado inspirado en la arquitectura serrana presidido por el empleo de la madera combinada con el granito. En este certamen compitió con otros pintores que también presentaron obras de temática albercana, caso de Francisco Echauz, quien

${ }^{97}$ Ibídem, p. 14.

${ }^{98}$ ADPS, Libro nº 186. Actas de la Comisión Gestora. Sesión del 28 de julio de 1941, fol. 245 y Sesión del 1 de septiembre de 1941, fol. 299.

${ }^{99}$ SANT-YAGO, "Al habla con... González Iglesias", El Adelanto, 2-VI-1954, p. 4. fue galardonado con la primera medalla, y José María Rodríguez Acosta, distinguido con el segundo premio ${ }^{100}$.

$\mathrm{Su}$ interés por esta localidad fue tal que el abulense publicó una monografía titulada La casa albercana, en la que analizaba sus característicos inmuebles ${ }^{101}$. Estos se distinguen por constar de tres alturas, de las cuales en los paramentos de la baja se emplea granito en el zócalo, mampostería en el lienzo y piedras en las aristas vivas, mientras que el resto de pisos están presididos por un entramado de madera y cantos rodados, aparte de estar volados, habitualmente apoyados sobre grandes ménsulas. En la última planta estas construcciones suelen contar con un corredor o solana ${ }^{102}$. Por lo demás, el facultativo que nos ocupa fue miembro de la Junta de Conservación de la localidad ${ }^{103}$ y los artículos que escribió entre 1951 y 1956 sobre su peculiar arquitectura fueron publicados por entregas en sus "Cien Hojas Folklóricas"104. La Alberca fue objeto de su estudio, no sólo desde el punto de vista arquitectónico ${ }^{105}$, sino también del humano, ya que analizó las costumbres y tradiciones de la zona ${ }^{106}$.

${ }^{100}$ Ibídem.

${ }^{101}$ L. GONZÁLEZ IGLESIAS, La casa albercana, Salamanca, 1945.

102 Véase también al respecto ÍDEM, "Nota sobre la construcción popular albercana". Revista de Tradiciones Populares, Tomo I , 1944, pp. 122-125.

${ }^{103}$ La Junta Oficial de Conservación del caserío y paisaje de La Alberca estaba conformada por miembros de la Diputación y del Ayuntamiento de esa localidad, además de otros que nada tenían que ver con estos organismos. El objetivo era conservar el patrimonio, la promoción del municipio y la organización de una exposición anual. "Constitución de la Junta Oficial de Conservación del caserío y paisaje de La Alberca", El Adelanto, 30-V-1942, p. 2.

104 Véase sobre el tema A. CARRIL RAMOS, Hojas folklóricas del Centro de Estudios Salmantinos 1951-1956, Salamanca, 1995.

${ }^{105}$ L. GONZÁLEZ IGLESIAS, "Parador turístico: La Alberca, Salamanca". Cortijos y Rascacielos, no 23, 1944, pp. 2-5.

106 Véase L. GONZÁLEZ IGLESIAS, El Protocolo del amor serrano, Salamanca, 1944. La Alberca fue el escena- 
Lorenzo González Iglesias llegó incluso a diseñar un parador de turismo (1939) para esta localidad, acorde con los principios compositivos propios de esta zona apenas señalados, aunque finalmente no se materializó" 107 . En la misma dirección, cabe destacar que el abulense fue el principal impulsor, junto con Eduardo de Rojas Ordoñez, Conde de Montarco, de la declaración de Ciudad Rodrigo como Conjunto Histórico Artístico el veintinueve de marzo de 1944, reconocimiento que finalmente alcanzón ${ }^{108}$. En 1948 intervino en esta localidad, tal como dieron a conocer José Ramón Nieto y María Teresa Paliza, en la reconstrucción de la casa renacentista de las Cuatro Calles ${ }^{109}$.

Vinculado a sus intereses etnográficos está el hecho de que a finales del año 1945 propuso la instalación de un museo folklórico en la sede de la Diputación, que no pasó de las intenciones. Según el propio técnico, "en la primera planta se iban a colocar tres cocinas y otras dependencias del hogar salmantino, correspondientes al llano, a la sierra y a la ribera. En el segundo piso se colocarían las

rio del libro escrito por el facultativo abulense titulado Protocolo del amor serrano, en el que abordó las relaciones entre sus habitantes. La primera edición data de 1944 y la segunda vio la luz un año después, a la que el autor añadió fotografías tomadas por él mismo, dibujos de Ricardo González Ubierna y un prólogo escrito por Antonio García Boiza. Rafael Santos Torroella destacó el interés de este título para "cuantos se dedican a estudios de etnografía nacional, pero también los méritos han de valorarse por las prendas literarias que lo acompañan. La prosa del señor González Iglesias es muy limpia, sosegada, llena de saber y de colorido; el rigor documental, la precisión en los datos que se aportan, no perjudica nunca a la fluidez y galanura de su estilo; de algunos párrafos diríamos que son bellísimos trozos de un poema en prosa, tanto por el ritmo interno de la frase como por la elegancia de su redacción". R. S. TORROELLA, "Los libros: El protocolo del amor serrano", El Adelanto, 6-II-1945, p. 4.

${ }^{107}$ A. PÉREZ-CARDENAL, "Por la casa rural salamanquina", El Adelanto, 22-X-1939, p. 3.

${ }^{108}$ J. R. NIETO GONZÁLEZ y M. T. PALIZA MONDUATE, Arquitecturas de Ciudad Rodrigo: catálogo de la Exposición de Trazas Arquitectónicas y Fotografías Antiguas, Ciudad Rodrigo, 1994, p. 150.

${ }^{109}$ Ibídem, pp. 57-59. vitrinas con las joyas y aderezos que utilizan las mujeres de las diversas regiones de la provincia, y los maniquíes que lucieran la rica variedad de trajes masculinos que se conservan en la misma. Finalmente, el tercer piso estaría destinado a hemeroteca y biblioteca"110.

\section{LA PARTICIPACIÓN DE GONZÁLEZ IGLESIAS EN EL CONCURSO DEL MONUMENTO CONMEMORATIVO DEL VIII CENTENARIO DE LA CIU- DAD DE SAN SEBASTIÁN}

En noviembre de 1949 el arquitecto abulense participó con el escultor José Luis Núñez Solé en este concurso, convocado con motivo del VIII Centenario de la fundación de la ciudad de San Sebastián, cuyos avatares han sido estudiados recientemente por José Javier Azanza López ${ }^{111}$. Según la información aportada por este autor, las bases del certamen estipulaban la obligación de que el proyecto estuviese redactado y firmado de manera conjunta por un arquitecto y un escultor, lo que justifica el equipo formado por Iglesias y Solén ${ }^{12}$. Además, el tema impuesto para todos los partícipes era el de Felipe IV haciendo entrega del Real Diploma que otorgaba el título de Ciudad a la localidad donostiarra, documento que portaría el monarca enrollado en su mano derecha. En el pedestal debía aparecer una inscripción con el nombre del rey y la fecha de concesión del título. Sólo concurrieron tres propuestas, la del escultor José Díez Bueno junto con el arquitecto Eduardo Lagarde Aramburu (18831950; titulado en 1907), la de Jorge Oteiza, quien colaboró con el facultativo José María

${ }^{110}$ R. AGUIRRE IBAÑEZ, "El Arte, desahuciado y en la vía pública. ¿Dónde instalamos el museo de pinturas y los talleres de los artistas?", El Adelanto, 15-XI1945, p. 3.

${ }^{111}$ J. J. AZANZA LÓPEZ, Crónica de un fracaso: Jorge Oteiza, Felipe IV y el VIII Centenario de San Sebastián (1950), Pamplona, 2013; ÍDEM, “Los concursos monumentales del VIII Centenario de San Sebastián (1950) en el contexto de la escultura pública española", Goya, no 346, 2014, pp. 68-85.

112 ÍDEM, “Los concursos...", p. 70. 
Ruiz Aizpiri (1908-1985; titulado en 1939) y la de los citados González Iglesias y Núñez Solép ${ }^{113}$. Las bases condicionaban un diseño absolutamente deudor con modelos propios del monumento conmemorativo de la etapa decimonónica. La solución que nos atañe constaba de un basamento, un pedestal y una estatua sedente. En cada una de las caras del primero aparecía labrada una de las palabras de la leyenda del escudo de San Sebastián, Fidelidad, Nobleza y Lealtad, acompañadas de medio relieves en clave alegórica de corpulentas figuras masculinas de cuerpo entero con poses que transmitían una actitud enérgica de inspiración clásica, pero de factura moderna. Esta receta fue indudablemente del agrado del escultor de este equipo, ya que cinco años más tarde, en 1955, Núñez Solé recurrió a este modelado en el diseño los relieves de la fachada principal de la entonces nueva sede de la Casa de la Falange -hasta el 2012 ha sido delegación de la Junta de Castilla y León-, situada en la Gran Vía con vuelta a la calle Palomo y rondín de Sancti Spiritus, proyectada por Fernando Población del Castillo ${ }^{114}$. Sobre el pedestal del concurso de San Sebastián aparecía el monarca sedente, en la posición exigida por la normativa, con rictus serio y con un modelado muy estilizado.

Sorprendentemente, la propuesta de Oteiza y Aizpiri era menos moderna, pues

\footnotetext{
${ }^{113}$ J. C. BRASAS EGIDO, Op. cit., pp. 23, 78 y 106.

${ }^{114}$ AMS, Fondo de obras, Caja 6257/4, Expediente 7; G. GOMBAU GUERRA, “La futura Casa de la Falange cerrará la Plaza del Caudillo formando frente a la Torre del Aire", El Adelanto, 16-I-1955, p. 4; "Casa Sindical", La Gaceta Regional, 11-II-1955, p. 4; "Ayer fue bendecida e inaugurada la nueva Casa Sindical", La Gaceta Regional, 12-II-1955, pp. 1 y 6; "Las Casas de la Falange en Salamanca”, La Gaceta Regional, 29-IX-1956, p. 5; “S. E. el Jefe de Estado inauguró en la tarde de ayer la Casa de Falange y el Palacio de Justicia en Salamanca", La Gaceta Regional, 30-IX-1956, p. 7.
}

en ella prevaleció el clasicismo, evidente en el basamento rectangular en el que dispuso las placas con los motivos señalados, aderezados con pilastras y retropilastras. Sobre ese pedestal apoyaba la estatua de Felipe IV sentado en un sillón, en este caso, apenas labrado. Sorprendentemente, el monumento nunca fue ejecutado, ya que el certamen se declaró desierto, circunstancia que, como justifica Azanza, pudo estar propiciada por un cambio de criterio por parte del Ayuntamiento, y a la falta de liquidez para materializar esta obra.

No obstante, esa no fue la única vez en la que González Iglesias participó en un proyecto de esa naturaleza, aunque, desafortunadamente, el resultado fue el mismo. En 1954 colaboró junto al escultor salmantino Agustín Casillas en un monumento dedicado al Corazón de María, cuya maqueta fue expuesta en la galería Artis. Este conjunto fue creado por encargo de un particular, pero nunca llegó a materializarse por motivos que desconocemos, así como la ubicación ${ }^{115}$. Según la fotografía publicada en la prensa salmantina, la obra constaba de un obelisco decorado en su base por figuras alegóricas de El Mundo, La Carne, El Demonio y La Fuente de la Pureza, y estaba rodeado por una plataforma semicircular con bancos de piedra decorados con la representación de los Sietes Dolores ${ }^{116}$.

\footnotetext{
115 “Exposición del proyecto de monumento al Corazón de María del que son autores el arquitecto González Iglesias y los escultores Casillas y Melero", El Adelanto, 20-VIII-1954, p. 3.

${ }^{116}$ Ibídem.
} 